\title{
Neuronal Degeneration and Associated Alterations in Cytokine and Protein in an Experimental Branch Retinal Venous Occlusion Model
}

Word count: 7745

Figures: 10

Authors:

\author{
Ian L. McAllister ${ }^{1,2,3}$ \\ Sarojini Vijayasekaran ${ }^{1,2}$ \\ Dan Zhang ${ }^{1,2}$ \\ Samuel McLenachan ${ }^{1,2}$ \\ Fred Kuanfu Chen ${ }^{1,2,3}$ \\ Dao-Yi $\mathrm{Yu}^{1,2}$
}

${ }^{1}$ Centre for Ophthalmology and Visual Science, The University of Western Australia, Perth, Australia.

${ }^{2}$ Lions Eye Institute, The University of Western Australia, Perth, Australia

${ }^{3}$ Department of Ophthalmology, Royal Perth Hospital, Perth, Australia

Corresponding author:

Professor I L McAllister

Lions Eye Institute,

Centre for Ophthalmology and Visual Science,

The University of Western Australia,

Nedlands, WA 6009,

Australia.

E-mail: ianmcallister@lei.org.au

Phone: 6189381870

Fax: 61893810766

Grant support was provided by the National Health and Medical Research Council of Australia 


\section{Abstract}

The mechanisms of neuronal degeneration and associated acute alterations in intraretinal cytokine and protein levels remain poorly understood in variable ischaemic retinopathies such as in branch retinal vein occlusion (BRVO). Herein we investigate neuronal damage and alterations in retinal cytokines and proteins in a pig model of acute BRVO. Twelve pigs had a BRVO induced photothrombotically in both eyes. Three pigs (6 eyes) each at 2, 6, 10 and 20 days were sacrificed together with an additional 3 control (6 eyes), enucleated, retinas dissected and processed. Apoptosis in the inner retina was determined by terminal deoxyynuclotidyl transferase mediated dUTP nick end labelling (TUNEL) and histology. Expression of glial acidic fibrillary protein (GFAP), aquaporin-4 (AQP4), inward rectifier potassium channel 10 protein $\left(\mathrm{K}_{\mathrm{ir}} 4.1\right)$ encoded by KCNJ10 gene, vascular endothelial growth factor (VEGF), stromal derived growth factor-1 $\alpha$ (SDF-1) encoded by CXCL12 gene and interleukin (IL) -6 and 8 were analysed by quantitative reverse transcription polymerase chain reaction (RT-qPCR) and immunohistochemistry. TUNEL labelling showed positive nuclei in the ganglion cell layer (GCL) and the inner nuclear layer (INL) which was significantly higher at 2 days after BRVO compared to other time points $(\mathrm{p}<0.05)$. Analysis by RT-qPCR revealed that compared with controls, BRVO significantly increased mRNA expression of GFAP at 6, 10 and 20, AQP4 at 20, VEGF at 6, SDF-1 at 20 and IL-8 at 2 and 10 days respectively $(\mathrm{p}<0.05): \mathrm{K}_{\mathrm{ir}} 4.1$ at 6 , VEGF at 2 and 10, and IL-6 at 2 days were significantly decreased $(\mathrm{p}<0.05)$. This study indicates that neural cell death occurs early in this acute model and the responses include inflammation and breakdown of osmohomeostasis as evidenced by the upregulation of GFAP and IL- 8 and down regulation of $\mathrm{K}_{\mathrm{ir}} 4.1$ associated with glyotic changes. Early short term VEGF upregulation seen may be related to involvement of Muller glial cells. These findings support the development of acute therapeutic strategies aimed at preservation of retinal neural cells as part of an overall management plan for BRVO. 
Key words:

retinal vein occlusion

Neurodegeneration

Apoptosis

Cytokine 


\section{Introduction}

Retinal vein occlusion (RVO) is the second most common cause of retinal vascular blindness after diabetic retinopathy (DR) affecting approximately 16 million people worldwide (Klein et al. 2000; Mitchell, Smith, and Chang 1996; Rogers, McIntosh, Cheung, et al. 2010). Approximately 1\% of individuals under 60 years of age are affected with the prevalence increasing to $5 \%$ in those over 80 years (Mitchell, Smith, and Chang 1996). RVO is a variable ischaemic microvascular retinal disease and remains a common cause of unilateral vision loss that may affect either a branch vein or the central retinal vein (CRVO). Of all retinal vein occlusions branch retinal vein occlusion (BRVO) is the most common and accounts for $80 \%$ of all vein occlusions (Mitchell, Smith, and Chang 1996; Klein et al. 2008). Without treatment, it can lead to a sustained loss of vision with a reported final mean visual acuity of $20 / 70$ with $23 \%$ of patients having a visual acuity of $\geq 20 / 200$ ('Argon laser photocoagulation for macular edema in branch vein occlusion. The Branch Vein Occlusion Study Group' 1984; Rogers, McIntosh, Lim, et al. 2010) . The pathogenesis of BRVO has been attributed to a combination of local changes in the vein at the arterio-venous crossing including degenerative changes of the vessel wall, compression, haemorheological changes, endothelial damage and deregulation of the thrombosis-fibrinolysis balance (Baglivo, Dosso, and Pournaras 1997; Frangieh et al. 1982; Kumar et al. 1998) resulting in retinal oedema, haemorrhage and neural degeneration. Programmed cell death (apoptosis) is considered a leading cause of neural degenerative mechanism invoked in these diseases (Donati et al. 2008; Joo et al. 1999). Understanding this mechanism at the molecular level may provide deeper insights into the processes involved and may be beneficial in the development of new therapeutic strategies. 
A common pathological sequel of RVOs is macular oedema (MO) (Wong and Scott 2010), where there is extra- and intracellular fluid accumulation, culminating in neural cell damage and death. It has been demonstrated that cytokines play a major role in the pathology of these diseases (Ki et al. 2007), however, the exact sequence of cytokine upregulation after the occlusion and the effects of these on retinal cellular elements remains to be elucidated. The development of MO has been attributed to the cytokine vascular endothelial growth factor (VEGF) and nitric oxide production. In recent years, intravitreal VEGF inhibitors have revolutionised treatment for these conditions confirming that MO is strongly associated with the upregulation of this cytokine (Campochiaro et al. 2010; Campochiaro et al. 2015) that enhances blood retinal barrier (BRB) breakdown, vascular permeability and leakage (Silva, Faria de Abreu, and Cunha-Vaz 1995). However, although this treatment improves visual outcomes in the short term over previous treatments such as grid laser, vision is not completely restored ('Argon laser photocoagulation for macular edema in branch vein occlusion. The Branch Vein Occlusion Study Group' 1984; Campochiaro et al. 2010; Campochiaro et al. 2015). Whilst these inhibitors control leakage, they do not resolve neural damage by apoptosis which occurs early, is progressive and currently irreversible.

It has been proven that the apoptotic processes in cells can be reversed by DNA repair in some circumstances, (Elmore 2007; Diez-Roux and Lang 1997) as in the case of experimental diabetic mice where leukostasis, retinal cell death and vascular permeability was abrogated in the absence of TNF $\alpha$ (Huang et al. 2011). In DR, another retinal microvascular disease, loss of the nerve fibre layer seems to occur early, often when there are only minimal retinal changes, and becomes worse with increasing severity of retinopathy. Retinal ganglion cell (RGC) death can be very slow and variable in the early clinical stages where they are in a pre-apoptotic state (Abu-El-Asrar et al. 2004). Damage to the retinal neural layers are seen clinically in both branch and central RVOs with OCT studies showing 
nerve fibre layer thinning even in the absence of capillary nonperfusion (Kim et al. 2014; Lima et al. 2011). Attenuating ischaemic neural injury and targeting these vulnerable cells in the inner retina before progression to an irreversible stage at the appropriate times would be exceedingly significant. However, in order to develop applicable neuroprotective strategies, it is necessary to understand the sequence of changes controlling neural damage from its initiation at the acute phase.

In this study, we investigate the timing of apoptosis and neural degeneration in the acute post-occlusion period (2-20 days), using our well-established pig model of BRVO (McAllister et al. 2009; McAllister et al. 2013; McAllister, Vijayasekaran, and Yu 2013). We have used terminal dUTP-mediated nick end labelling (TUNEL) which labels fragmented DNA, histology including ultra-structure to assess pyknosis (early changes of nuclear shrinkage and chromatin condensation) (Kerr, Wyllie, and Currie 1972) and architectural changes that occur in this acute phase. Concurrently, we examined changes in retinal gene expression occurring in the acute phase of BRVO by quantitative reverse transcription polymerase chain reaction (RT-qPCR) targeting a panel of cytokines (VEGF, SDF-1 encoded by CXCL12 gene, IL6, IL8), membrane-associated channels (AQP4, Kir 4.1 encoded by KCNJ10 gene) and markers of gliosis (GFAP). Protein expression and localization was examined by immunostaining. These markers were chosen as they have various pathological effects including gliosis, MO, angiogenesis and inflammation in vascular retinopathies (Bringmann et al. 2006) (Sapieha et al. 2010).

\section{Materials and methods}

\section{$2.1 \quad$ Animals}


All animal procedures were approved by the Animal Ethics Committee of the University of Western Australia and conformed to the ARVO Statement for the Use of Animals in Ophthalmic and Vision Research and the policies in the "Guide to the Care and Use of Laboratory Animals" issued by the National Institutes of Health. All efforts were used to minimise pain and suffering during surgery and housed under great care at all times to provide an untroubled and comfortable environment. The pig has been chosen for this study as it has been established as a suitable model having a similar retinal architecture and replicates the features in BRVO as demonstrated in several of our previous clinical and histological studies at different time points from 1 to 11 weeks (McAllister et al. 2009; McAllister et al. 2013; McAllister, Vijayasekaran, and Yu 2013) (Fig. 1).

\subsection{Surgery and tissue processing}

A total of 15 pigs (30 eyes) were used in this study (aged 10 weeks, body weight $\sim 25$ $\mathrm{kg}$ ). Of the 15 pigs, twelve were anaesthetized and sedated with an intramuscular injection using a combination of Zoletil 100 (Tiletamine hypochloride-Zolazepam hypochloride) (4.4 $\mathrm{mg} / \mathrm{Kg}$ ) and Illium Xylazine-100 (Xylazine hydrochloride) $(2.2 \mathrm{mg} / \mathrm{Kg}$ ). They were then intubated, ventilated and maintained on isoflurane in $100 \%$ oxygen. Pupillary dilation was achieved with tropicamide $1 \%$ and phenylephrine hydrochloride $2.5 \%$.

Baseline assessment in all eyes included binocular indirect ophthalmoscopy to exclude pre-existing retinal disorders. After intravenous injection via an ear vein of 10 $\mathrm{mg} / \mathrm{Kg}$ of Rose Bengal dye (Sigma Aldrich, St. Louis, MO, USA), which is a dye with peak absorption of light close to the wavelength of the argon laser. This allows an intravascular thrombus to be created with minimal damage to the vessel wall if appropriate laser powers are used. A photothrombotic BRVO was created in an inferior vein adjacent to the optic disc 
in both eyes of each pig using an argon green laser, $532 \mathrm{~nm}$ wavelength, (Ellex Medical Lasers Ltd., Adelaide, Australia) as described previously (McAllister et al. 2009; McAllister et al. 2013; McAllister, Vijayasekaran, and Yu 2013). This vein was chosen as it creates a small superior field defect and leaves the horizontal and inferior fields unaffected.

Chloramphenicol ointment 1\% (Sigma Pharmaceuticals Ltd, Victoria, Australia) was applied to the eyes after surgery. After surgery the pigs were allowed to recover and were sacrificed at 2, 6, 10 and 20-day post-surgery. The remaining three pigs were used as controls and sacrificed with no intervention. Immediately after sacrifice, the eyes were enucleated, the anterior segment was removed and using an $8 \mathrm{~mm}$ diameter corneal trephine, 2 discs of retina on either side of the occluded vessel outside the focal area of the laser burn and within the area of the BRVO in the retina were cut. One disc was fixed in $4 \%$ paraformaldehyde overnight at $4^{\circ} \mathrm{C}$ and processed in paraffin for TUNEL, basic histology and immunohistochemistry and the other for RT-qPCR from both right and left eyes and from similar areas of the normal eyes without a BRVO. In addition, 2 X $2 \mathrm{~mm}$ pieces adjacent to the discs were cut and fixed in $2.5 \%$ glutaraldehyde in $0.1 \mathrm{M}$ phosphate buffer and processed in epoxy resin for transmission electron microscopy (TEM).

\subsection{TUNEL}

TUNEL technique which is widely employed to measure DNA fragmentation for highlighting apoptotic cells in tissues was used to detect apoptotic degeneration. Briefly $6 \mu \mathrm{m}$ sections were deparaffinised, permeabilised by subjection to heating in a microwave for 4 minutes in sodium citrate buffer $\mathrm{pH} 6.0$ and labelled according to manufacturer's protocol (In situ Fluorescein cell death kit, Roche applied science, Penzberg, Germany). Sections were labelled by incubating with TUNEL reaction mixture consisting of $50 \mu$ l of enzyme solution (terminal deoxynucleotidyl transferase) and $450 \mu 1$ of label solution (nucleotide mixture fluorescein - dUTP) in a humidified chamber at $37^{\circ} \mathrm{C}$ in the dark for 60 minutes. Positive 
and negative controls were also performed by incubating with Dnase I recombinant (1500U/ml in $50 \mathrm{mM}$ Tris $\mathrm{pH} 7.5,10 \mathrm{mM} \mathrm{MgCl} 2,1 \mathrm{mg} / \mathrm{ml} \mathrm{BSA})$ for 10 minutes at room temperature to induce DNA strand breaks and with label solution only respectively prior to labelling. Slides were rinsed in PBS containing a nuclear stain (Hoechst) (Sigma-Aldrich, St. Louis, MO, USA) which stains the DNA of all cells (Crowley, Marfell, and Waterhouse 2016) (prot087221), mounted with antifade medium and viewed under an epifluorescent microscope equipped with fluorescence relevant detection filter (excitation /emission maxima $495 / 519 \mathrm{~nm}$ ) and photographs were taken at a preset setting on the microscope at a magnification of X 60. TUNEL positive cells and all Hoechst stained cells were manually counted.

\subsection{Histology}

Basic histological analysis was performed on haematoxylin and eosin stained $6 \mu \mathrm{m}$ paraffin sections and viewed by light microscopy (LM). In addition, both normal looking and dark shrunken pyknotic nuclei (as TUNEL stains only fragmented nuclei as opposed to hyper condensed pyknotic nuclei) (Crowley, Marfell, and Waterhouse 2016) (prot087221) were manually counted as above. Ultra-structural changes were analysed on $0.1 \mu \mathrm{m}$ ultrathin epoxy resin sections stained with uranyl acetate and lead citrate and viewed by TEM (Philips CM10-2; Philips Electron Optical, Eindhoven, The Netherlands).

\section{$2.5 R T-q P C R$}

RT-qPCR was employed as it is a well-defined method of quantifying gene expression levels. The neural retinas were dissected out from the discs and stored in RNAlater (QIAGEN, Hilden, Germany) at $4^{\circ} \mathrm{C}$ for one week then transferred to $-20^{\circ} \mathrm{C}$. Total RNA was extracted using RNeasy Plus Micro Kit and QIAshredder (QIAGEN). RNA purity was assessed by a NanoDrop ND-2000 spectrophotometer (Thermo Fisher Scientific, Waltham, MA, USA). First- 
strand cDNA was synthesized using $0.5-1 \mu \mathrm{g}$ of total RNA and RT ${ }^{2}$ First Strand Kit (QIAGEN) according to the supplier's protocol. Each qPCR reaction was performed in a $25 \mu 1$ mixture containing $1 \mu \mathrm{l}$ (15-20ng) of cDNA, a pair of porcine-specific primers $(0.4 \mu \mathrm{M})$ and $\mathrm{RT}^{2}$ SYBR-Green qRT-PCR Master Mix (QIAGEN). The primers used in qPCR were GFAP (PPS00012A), AQP4 (PPS01854A), K 4.1 (PPS07806A), VEGF (PPS00495A), SDF-1 (PPSO1281A), IL-6 (PPS00991A), IL8 (PPS00237A) and glyceraldehyde-3-phosphate dehydrogenase (GAPDH, PPS00192A) (RT² qPCR Primer Assay, QIAGEN). In the CFX Connect Real-Time System (Bio-Rad, Hercules, CA, USA), thermocycling conditions were performed as: $95^{\circ} \mathrm{C}$ for 10 minutes, 40 cycles of $95^{\circ} \mathrm{C}$ for 10 seconds and $60^{\circ} \mathrm{C}$ for 20 seconds. The PCR threshold cycle $\left(\mathrm{C}_{\mathrm{T}}\right)$ values were determined by Bio-Rad CFX Manager software version 3.0. All reactions were performed in triplets in two separate runs. In all experiments the relative gene expression levels were normalised against pig house-keeping gene GAPDH. Relative quantitation of gene expression levels in the retinas with BRVO and normal retinas were evaluated using the $-2^{\Delta \Delta \mathrm{C}} \mathrm{T}$ method (Livak and Schmittgen 2001).

\subsection{Immunohistochemistry}

Six- $\mu \mathrm{m}$ thick sections were cut on a microtome (Leica 2040). Deparaffinised sections underwent antigen retrieval (permeabilised) and immunofluorescence staining as described previously (McAllister et al. 2009). Briefly, the sections were treated with blocking serum and then incubated with primary antibody (Table 1). After 2 hours at room temperature or overnight at $4^{\circ} \mathrm{C}$ incubation respectively they were incubated again with the relevant fluorescence Alexa fluor 488 or Alexa fluor 546-conjugated secondary antibody (Invitrogen, Thermo Fisher Scientific, MA, USA) for 1 hour. After each incubation 3 X 3-minute phosphate buffered saline (PBS) washes were performed. Slides were mounted with non-fade mounting medium (Hydromount, National Diagnostics, GA, USA). Negative controls with the omission of the primary antibody and with isotype control was performed. The distribution of 
the labelled protein was visualized under an epifluorescent microscope (Nikon Eclipse E-800: Nikon, Tokyo, Japan) equipped with fluorescence relevant detection filter (excitation / emission maxima $495 / 519 \mathrm{~nm}$ or $556 / 573 \mathrm{~nm}$ ) and photographs were taken at a preset setting on the microscope. Qualitative analysis of immunohistochemistry was performed for the main purpose of determining the tissue regions which showed reactivity.

Table 1. List of primary antibodies used in this study

\begin{tabular}{llc}
\hline Primary antibody & Source & Dilution \\
\hline Polyclonal rabbit anti-cow GFAP & Dako, Glostrup, Denmark & $1: 50$ \\
Polyclonal goat anti-human AQP4 & Santa-Cruz Biotech. Inc. Europe & $1: 100$ \\
Polyclonal rabbit anti-human Kir 4.1 & Alomone lab, Jerusalem, Israel & $1: 200$ \\
Polyclonal rabbit anti-humanVEGFA Santa-Cruz Biotech. Inc. Europe & $1: 50$ \\
Polyclonal rabbit anti-human SDF-1 & Santa-Cruz Biotech. Inc. Europe & $1: 50$ \\
Polyclonal rabbit anti-human IL-6 & Abcam Australia & $1: 100$ \\
Monoclonal mouse anti-human IL-8 & Abcam Australia & $1: 50$ \\
\hline
\end{tabular}

Primary antibodies were validated by western blotting against pig retinal proteins obtained from additional normal pig eyes. Pig retinal tissue was lysed in RIPA lysis buffer (SigmaAldrich, St. Louis, MO, USA) with 1\% protein inhibitor cocktail (Sigma) followed by shaking at $4^{\circ} \mathrm{C}$ for 1 hour. The lysate was then centrifuged at 13,000 rpm for 30 minutes at $4^{\circ} \mathrm{C}$ and the supernatant collected. Protein concentration of the lysate was determined by BioRad Protein Assay (Bio-Rad, Hercules, CA, USA). Twenty micrograms of total protein from tissue lysates was mixed with 1x NuPAGE Novex LDS Sample Buffer (Invitrogen, Thermo Fisher, Scientific, Waltham MA, USA) and heated at $70^{\circ} \mathrm{C}$ for 10 mins before loading onto a NuPAGE 4-12\% Bis-Tris gel (Invitrogen). Protein samples were separated by gel 
electrophoresis in MES SDS Running buffer (Invitrogen) and then transferred onto a PVDF membrane (Immobilon-FL, Merck Millipore, Billerica, MA, USA) at $80 \mathrm{~V}$ for 90 minutes in transfer buffer (25 mM Tris, $190 \mathrm{mM}$ glycine, 20\% methanol, $\mathrm{pH} 8.3$ ). After transfer, the membrane was incubated with blocking buffer $(5 \%$ bovine serum albumin in tris-buffered saline) at room temperature for 1 hour. The membrane then was incubated with anti-IL6 antibody (1:1000), anti-K $\mathrm{K}_{\text {ir }} 4.1$ antibody $(1: 200)$, anti-GFAP antibody (1:1000), anti-VEGF antibody (1:200), anti-IL8 antibody (1:2000), anti-APQ4 antibody (1:200), anti-SDF-1 antibody (1:200), isotype controls, mouse IgG1 (1:500), rabbit IgG (1:40) and Goat IgG (1:40) in blocking buffer with $0.1 \%$ Tween 20 at $4^{\circ} \mathrm{C}$ overnight. After washing in tris-buffered saline with $0.1 \%$ Tween 20 (TBST) 3 times, the membrane was incubated with IRDye $800 \mathrm{CW}$ donkey anti-goat, goat anti-mouse, or goat anti-rabbit IgG (1:10,000; LI-COR) in blocking buffer plus $0.1 \%$ Tween 20 and $0.01 \%$ SDS for 1 hour at room temperature. After three TBST washes, the membrane was washed once with tris-buffered saline without Tween 20 . The membrane was then imaged at $700 \mathrm{~nm}$ and $800 \mathrm{~nm}$ wavelength by the Odyssey Infrared Imager (Model 9120, LI-COR).

\subsection{Statistical analysis}

All data was analysed statistically using SigmaStat 3.5 (Systat Software, San Jose, CA, USA). For cell death and pyknosis a total of 5 eyes were used for each group. Four images from randomly selected slides were examined from each sample (eye) of each group. In each image TUNEL positive cells and all Hoechst stained nuclei were manually counted. Haematoxylin and eosin stained pyknotic and non-pyknotic nuclei were also counted. For cell death and pyknosis, values are expressed as a fraction (percentage) of total number of cells respectively (Crowley et al. 2016) (top070318): Data for multiple comparisons between groups was performed with one-way analysis of variance and Dunn's method. RT-qPCR data was analysed by t-test comparing normal and treated eyes and with one-way analysis of 
variance and Kruskal-Wallis test and Dunn's method for multiple comparison. Probability values $<0.05$ were considered as statistically significant. Data expressed as graphs with mean \pm SEM respectively. A total of 4-6 samples (eyes) were assayed in each group.

\section{Results}

\subsection{Branch retinal vein occlusion}

Immediately after laser treatment of the pig eyes, engorgement of the distal vein and scattered intraretinal haemorrhages were seen, indicating an occlusion had been created. The laser burn was clearly distinguishable on macroscopic examination of the enucleated eye cups in all the eyes in which a vein occlusion was induced. In previous studies, similar photothrombosis in pig retinas have confirmed the presence of an occlusion (Fig.1) (McAllister et al. 2009; McAllister, Vijayasekaran, and Yu 2013).

\subsection{Neurodegeneration}

\subsubsection{TUNEL}

TUNEL staining revealed a large number of dying cells in the ganglion cell layer (GCL) and inner nuclear layer (INL) at 2 days after BRVO with fewer labelled cells observed at all other time points (Fig. 2). Quantification of the percentage of TUNEL positive nuclei showed a significantly higher number in the GCL at 2 days $(\mathrm{p}<0.05)$ compared to all other time points $(6,10$ and 20 days) and the normal retina. There was no significant difference between groups at the other time points after BRVO (normal versus 6,10 and 20; 6 versus 10 and 20; 10 versus 20 days respectively).

In the INL there was a significantly higher number at 2 days compared to 10 days post-BRVO and the normal retina $(\mathrm{p}<0.05)$. There was no significant difference between 2 days and the other two BRVO groups (6 and 20 days) and between groups at the other time 
points after BRVO (normal versus 6, 10 and 20; 6 versus 10 and 20; 10 versus 20 days respectively ( $p>0.05)$ (Fig. 3).

\subsubsection{Pyknotic cells}

Quantification of the percentage of pyknotic cells displaying condensed dark nuclei on haematoxylin eosin sections viewed by LM showed a significantly higher number in the GCL at 2 days compared to 6 days and the normal retina $(\mathrm{p}<0.05)$, however, there was no significant difference at 2 days compared to 10 and 20 days $(p>0.05)$ post occlusion. There was no significant difference between groups at the other time points after BRVO (normal versus 6,10 and 20; 6 versus 10 and 20; 10 versus 20 days respectively) $(\mathrm{p}>0.05)$.

In the INL significantly higher number of pyknotic cells at 2 days compared to normal, and all other time points $(6,10$ and 20 days $)$ after BRVO $(\mathrm{p}<0.05)$ was seen. There was no significant difference between groups at the other time points after BRVO (normal versus 6,10 and 20; 6 versus 10 and 20; 10 versus 20 days respectively) ( $\mathrm{p}>0.05)$ (Fig.4).

\subsubsection{Morphology}

Basic histology of the normal retina showed healthy well organized layers of cells whereas the eyes with BRVO revealed degenerative changes within the cells of the inner retinal layers at all time points. Vacant spaces and pyknotic nuclei were seen in the GCL and the INL (Fig. 5).

TEM of retinal sections at 6,10 and 20 days after BRVO confirmed and extended these findings. The inner limiting membrane (ILM) showed reduced end-feet, degenerating astrocytes and cellular debris. There were degenerating cells in the GCL and in the INL some of the Muller cells appeared pyknotic. Muller fibres showed irregularity and disorganisation with swollen mitochondria. Vacuoles with membranous debris were also 
seen. At 2 days TEM confirmed the presence of apoptosis where there were cells that had undergone alterations in their nuclei and cytosol typical of apoptotic cells in addition to cells with vacuoles that may be undergoing necrosis (Fig. 6).

\subsection{Changes in Gene and Protein Expression}

Changes in gene and protein expression in the post occlusion period were assessed by RT-qPCR (Fig.7) and immunofluorescence (Fig.8-10) analyses. Immunostaining controls, in which the primary antibody was omitted or replaced with an isotype control antibody, demonstrated an absence of specific staining (GFAP, AQP4, $\mathrm{K}_{\mathrm{ir}}$ 4.1, VEGF, SDF-1, IL-6 and -8; Figs. 8 F, L, R, Figs. $9 \mathrm{~F}$ and L, Figs. $10 \mathrm{~F}$ and L respectively). Primary antibodies were validated by western blot analysis (supplementary data).

\subsubsection{GFAP}

RT-qPCR analysis for GFAP mRNA showed significantly higher levels in the BRVO treated eyes at 6,10 and 20 days compared to normal retinas $(\mathrm{p}<0.05)$. Although higher level of GFAP was seen at 2 days it did not reach statistical significance $(p>0.05)$. There was no significant difference among the BRVO treated groups $(2,6,10$ and 20 days post occlusion time points) $(\mathrm{p}>0.05)$.

In the normal retinas intense immune-reactivity of GFAP was seen in the area of the ILM in the astrocytes with hardly any reactivity in the Muller cells. In the retinas with BRVO after 2 days mild reactivity was seen in the astrocytes and in the Muller fibres, at 6 days, reactivity was seen predominantly in the Muller fibres and less in the astrocytes. At 10 days and 20 days strong staining was seen in the ILM and in both Muller cells and astrocytes (Fig. 8 A-E).

\subsubsection{AQP4}


Analysis of AQP4 mRNA by RT-qPCR showed a significantly higher level at 20 days $(p<0.05)$ and no significant difference at 2, 6 and 10 days $(p>0.05)$ in the BRVO treated eyes compared to normal retinas. There was also a significantly higher level at 20 days compared to 2 days in the BRVO treated eyes $(p<0.05)$ with no significance among the other BRVO treated groups (2 versus 6 and 10, 6 versus 10 and 20, 10 versus 20 days post occlusion time points respectively) $(\mathrm{p}>0.05)$.

AQP4 immunoreactivity was detected in the ILM, nerve fibre and, inner and outer plexiform layer and at the perivascular regions of the INL of the normal and BRVO retinas at all time points (Fig. 8 G-K).

\subsubsection{KCNJ10 $\left(K_{\text {ir }} 4.1\right)$}

RT-qPCR mRNA analysis revealed significantly lower levels of KCNJ10 in the BRVO treated retinas at 6 days compared to normal retinas $(\mathrm{p}<0.05)$. Although lower level of $K C N J 10$ was seen at 2 days than normal retinas, it did not reach statistical significance $(p>0.05)$. There was no significant difference among the BRVO treated groups $(2,6,10$ and 20 days post occlusion time points) $(\mathrm{p}>0.05)$.

Kir4.1 immunoreactivity was detected in the ILM, nerve fibre layer, GCL, inner plexiform layer, INL and in the Muller fibres of the normal retinas. Weak staining was seen in the BRVO retinas at all time points. (Fig.8 M-Q).

\subsubsection{VEGF}

RT-qPCR analysis showed a significantly higher level of VEGF at 6 days and significantly lower levels at 2 and 10 days in the treated retinas with BRVO compared to normal retinas $(\mathrm{p}<0.05)$. There was also a significantly higher level at 6 days compared to 10 days in BRVO treated retinas with no significance among the other BRVO treated groups 
( 2 versus 6,10 and 20,6 versus 20, 10 versus 20 days post occlusion time points respectively) $(\mathrm{p}>0.05)$

Immunoreactivity was diffuse and was predominantly in the GCL and INL in normal and BRVO retinas (Fig. 9 A-E).

\subsubsection{CXCL12 (SDF-1)}

RT-qPCR analysis of mRNA CXCL12 showed significantly reduced levels at 2 days and showed a significant increase at 20 days in the BRVO compared to normal retinas $(\mathrm{p}<$ 0.05). There was no significant difference among the BRVO treated groups $(2,6,10$ and 20 days post occlusion time points) $(\mathrm{p}>0.05)$.

Immunoreactivity of SDF-1 was seen in the ILM, GCL, INL and outer plexiform layer. The staining was diffuse through the retinal layers (Fig. 9 G-K).

\subsubsection{IL-6}

RT-qPCR analysis showed significantly reduced levels in IL6 mRNA in the retinas with BRVO at 2 days compared to normal retinas $(\mathrm{p}<0.05)$. Although there was an increase in the levels at 10 and 20 days it did not reach significance. There was no significant difference among the BRVO treated groups $(2,6,10$ and 20 days post occlusion time points) $(\mathrm{p}>0.05)$.

IL-6 immunoreactivity was detected in the ILM, nerve fibre and GCL, diffuse staining in the inner plexiform layer and in the INL of the normal and BRVO retinas at all-time points (Fig. 10 A-E).

\subsubsection{IL-8}

RT-qPCR analysis showed significantly higher levels of IL-8 mRNA in the retinas at 2 and 10 days with BRVO compared to normal retinas $(\mathrm{p}<0.05)$. Although, up regulation was 
seen at 6 days did not reach significance $(p>0.05)$. There was no significant difference among the BRVO treated groups $(2,6,10$ and 20 days post occlusion time points) $(\mathrm{p}>0.05)$.

IL-8 immunoreactivity was seen in the BRVO retinas at all time points. Weak staining was seen in the normal retinas. It was detected in the GCL, INL and diffuse staining in the plexiform layers of all BRVO retinas and in the ILM of retinas at 2, 6 and 10 days respectively (Figure $10 \mathrm{G}-\mathrm{K}$ ).

\section{Discussion}

The success in public and referrer awareness with macular degeneration has led to much earlier presentation of patients with this condition as well as other causes of unilateral visual loss including BRVOs. There is now potential for acute stage treatments including those aimed at preserving retinal neural elements providing the sequence of events following the BRVO is better understood.

The pig model was chosen for this study as its eye is very similar to the human in terms of anatomy, vasculature, similar marker distribution and histogenesis progression (Guduric-Fuchs et al. 2009) as compared to other non-primate mammals and a BRVO can be successfully created as in several studies in the past (McAllister et al. 2009; McAllister, Vijayasekaran, and Yu 2013). Among non-primate models pigs have been suggested as the best model for BRVO. The rodent eye is very small and appropriate focusing of even the smallest available laser beam is extremely difficult (Khayat et al. 2017) The use of Rose Bengal as a photo-enhancing agent allows the creation of an intraluminal thrombus with minimal damage to the vein and overlying retina. Whilst it does not exactly replicate what happens in patients with BRVO as it creates an acute obstruction, it does show the early classical features (Khayat et al. 2017). It is useful as a model to understand the sequence of molecular changes within the retina as the exact timepoint of the obstruction to venous 
outflow is known whilst in humans with BRVO the level of obstruction and associated clinical signs appear to progress over several months before gradually resolving.

To assess neurodegeneration, TUNEL staining to detect dying cells with fragmented DNA (Crowley, Marfell, and Waterhouse 2016) and haematoxylin and eosin staining to identify pyknotic nuclei (hyper condensed DNA) which is an early feature in apoptosis not detected by TUNEL staining, was employed . The TUNEL assay is sensitive, and its methodology has been significantly improved, however, since necrotic cells may also be stained (Zille et al. 2012) by this technique, we also performed TEM to confirm these cells were apoptotic.

Cytokines and proteins play a major role in the preservation or destruction of tissue. $\mathrm{BRB}$ breakdown and MO are associated with the changes in their regulation (Ki et al. 2007). In the present study we investigated these changes in the acute phase and correlated them with histological and apoptotic intraretinal changes. A widely accepted semi quantitative scoring system for immunohistochemistry does not exist as yet and automated systems are not accurate in the interpretation of certain tissues (Fedchenko and Reifenrath 2014) such as the retina. Hence, RT-qPCR was employed to quantitate precisely the change in the gene expression levels of cytokines and proteins whereas immunofluorescence was used for qualitative analysis mainly to detect the cell and tissue locations at which the antigens were immunoreactive.

Muller cells play a vital role in retinal homeostasis. They appear to be amongst the first responders to a variety of injuries to the retina and undergo reactive gliosis (Bringmann et al. 2009). Retinal Muller cell injury is associated directly or indirectly with up or down regulation of cytokines inducing reactive gliosis aimed at mitigating and preventing further damage to the neurons in the retina. However, although the cytokines secreted are initially neuro-protective, overproduction may result in severe gliosis resulting in detrimental effects 
to neuronal and photoreceptor cell viability. Gliosis is characterised by the upregulation of GFAP. GFAP changes in the Muller cells were investigated as it is amongst the earliest and most sensitive manifestation to retinal injury (Rehak et al. 2009). Reactive glial cells can in turn induce cytokine production (Khandelwal, Herman, and Moussa 2011). In our study in the retinas with a BRVO the GFAP mRNA levels were upregulated by 2 days and reached significance at 6,10 and 20 days with peak upregulation seen at 10 days. Staining was localised in both the astrocytes and in the full extent of the Muller cells. This also correlates with the degree of apoptosis seen in the inner retina in the acute stage. LM and TEM also confirmed degenerative changes in astrocytes and Muller cells and their fibres in the BRVO retinas. The pattern of staining of GFAP in the normal retinas was confined to the astrocytes with minimal reactivity seen in the normal healthy Muller cells as has been demonstrated previously (Eisenfeld, Bunt-Milam, and Sarthy 1984).

Muller cells are richly endowed with specialised integral membrane proteins AQP4 and $\mathrm{K}_{\mathrm{ir}} 4.1$ involved in water permeability mediating iso-osmotic fluid exchange (Pannicke et al. 2004). These proteins were also analysed in our study as they are closely associated with retinal oedema. In this study, there was a significant upregulation at 20 days of AQP4 mRNA and no significant difference at the other time points between normal retina and those with BRVO suggesting that water uptake by the Muller cells mediated by AQP4 is not affected in the acute phase of BRVO but may become more significant at later stages with the development of retinal oedema. Similar to these findings AQP4 was largely unaltered in the early stages of a rat model of retinal transient ischemic reperfusion whilst Muller cells within hours significantly down regulate $\mathrm{K}_{\mathrm{ir}} 4.1$ channels, swell and become reactive resulting in ganglion cell death) (Pannicke et al. 2004). $\mathrm{K}_{\mathrm{ir}} 4.1$ levels in our study was similarly significantly down regulated in the BRVO retinas at 6 days compared to the normal retinas, another feature indicative of acute changes in Muller cells. The consequence of such an event 
would lead to an inability to extrude $\mathrm{K}+$, intracellular accumulation of $\mathrm{K}+$, increased intracellular osmotic pressure, an influx of water from the blood into the cells culminating in glial cell swelling and the onset of retinal and MO. Reactive changes such as swelling and death of neurons may not be attributed directly to BRB break down and vascular leakage and may reflect impairment of fluid (metabolic water) clearance (Lobo, Bernardes, and CunhaVaz 2000). It has been suggested that unlike $K_{\text {ir }} 4.1$, the membrane anchoring protein syntrophin of AQP4 is insensitive to ischaemia (Puwarawuttipanit et al. 2006) and this may be the reason why AQP4 was not down regulated in our study. It appears that the most severe neural damage within the retina after an acute BRVO in this model occurs within the first week depicted by the upregulation of GFAP, down regulation of $\mathrm{K}_{\mathrm{ir}} 4.1$ (KCNJ10) expression and the significant loss of GCL and INL cells to apoptosis at 2 days, depicted by TUNEL positive nuclei seen by LM and confirmed by TEM.

The results of this study demonstrated a significant number of TUNEL positive dying cells peaking at 2 days after BRVO in the GCL as seen in previous studies in minipigs with an occlusion (Donati et al. 2008). Apoptosis and inner retinal damage also appears to occur in the early stages of diabetic humans before retinopathy is seen as similar changes were detected in post-mortem eyes (Barber et al. 1998). In the present study, pyknotic cells in the GCL were significantly increased at 2 days post occlusion compared to normal retina. Increased numbers of pyknotic cells were also observed from 6-20 days post occlusion, however these results did not achieve statistical significance (Fig.4), suggesting that pyknosis does not cease instantaneously but could fluctuate at least up to 3 weeks after BRVO. This gives a reasonable window of time for neuroprotective agents to be effectively administered to modulate the associated pathways and rescue the less damaged vulnerable cells which are at an early and potentially reversible phase of apoptosis. The cytoplasmic vacuoles seen at all time points may represent necrotic cell death. Apoptosis and necrosis can occur 
independently, sequentially or simultaneously depending on the intensity of the stimulus (Elmore 2007). This has also been seen in previous studies in the retina and in brain infarction (Donati et al. 2008; Kovacs et al. 1996) prior to recovery in which some of the less damaged cells may be restored. BRVO affects predominantly the inner retina and these adverse changes seen are most likely due to the BRVO rather than laser damage as sampling was performed outside of the focal area of laser damage. Whilst these changes may not replicate the crescendo degree of obstruction occurring in many human subjects with this condition they do imply damage to the inner retina occurs early and this may be a potential area for therapeutic intervention in the future.

Vascular leakage in RVO is associated with hypoxia induced up-regulation of VEGF, together with the increased hydrostatic pressure that occurs due to the obstruction to venous outflow (Kaneda et al. 2011). In previous studies it appears that VEGF in BRVO may be upregulated after the acute event initiated by the activation of VEGF receptors (Martin, Galisteo, and Gutkind 2009). VEGF receptors flt-1 (VEGFR-1) and FLK-1 (VEGFR-2) are present in the GCL and INL cells and in the Muller cell processes respectively (Vinores et al. 2001). In our study, however, there was an initial down regulation of VEGF mRNA expression at 2 days which may be attributed to the loss of a large number of these cells to apoptosis in the GCL and INL resulting in reduced secretion of VEGF at this time point. VEGF expression was noted to be upregulated at 6 days in our study and then decreased at 10 and 20 days. This is similar to other animal acute BRVO and CRVO studies where expression of VEGF upregulation is transient in the acute stage (Rehak et al. 2009) (Rehak et al. 2011). These studies demonstrated VEGF is significantly upregulated at 1 day after a retinal vein occlusion followed by down regulation at 3 and 7 days respectively. Another study (Ebneter et al. 2015) investigating the levels of VEGF in mice by enzyme-linked immunosorbent assay showed similar results being significantly upregulated at 1 day and returning to normal levels 
at 3 days. The rising and falling of VEGF levels may reflect immediate necrotic events as seen in a previous study (Donati et al. 2008).

A direct relationship between IL-6 and VEGF has been previously demonstrated in the aqueous humour of diabetic patients. (Funatsu et al. 2001). This however was not seen in our study where intra retinal changes in gene expression of these cytokines were evaluated rather than intraocular fluid levels. IL-6 expression was significantly downregulated at 2 days although it did show a trend towards higher levels at 10 and 20 days. There are variable reports on the regulation of IL-6 after BRVO. Previous animal studies have shown acute significant upregulation of IL-6 gene expression in the neural retina in CRVO induced rats (Rehak et al. 2011). However, similar to our findings, Lee et al. (Lee et al. 2012) by multiplex array assay reported that aqueous levels of IL-6 in BRVO patients were not significantly different from the control group (without ocular or systemic diseases) while VEGF was upregulated. They suggested that the role of inflammation is less influential in BRVO compared to diabetic retinopathy and in BRVO abrupt blockage may result in sudden upregulation of VEGF.

The results of clinical studies with VEGF inhibitors imply that VEGF is a dominant cytokine in BRVO at least in the later stages in humans. VEGF is present in normal adult eyes in the absence of retinal injury (Kim et al. 1999). Although VEGF is considered a major angiogenic factor that increases microvascular permeability, aqueous levels of VEGF in BRVO patients have been shown to vary. Previous studies have shown VEGF upregulated (Noma et al. 2005) in some and no change or reduced levels in others (Funk et al. 2009; Lim 2011). Most of the information concerning intraocular cytokine changes after RVO stems from human aqueous or vitreous samples in patients with variable and often significant durations of the occlusion (Noma et al. 2005; Funatsu et al. 2012; Noma et al. 2006; Noma et al. 2008; Noma et al. 2010; Noma, Mimura, and Eguchi 2013; Okunuki et al. 2011). These 
studies have shown various degrees of elevated levels of VEGF in both the aqueous and vitreous with the levels dependant on the area of involvement and the degree of retinal ischemia. The role of VEGF in patients as early as 3 weeks after an occlusion has not been studied to the best of our knowledge. Both the BRAVO study and the VIBRANT study investigating the role of anti-VEGF in BRVO enrolled patients 40-60+ days post diagnosis of the BRVO. The actual time the BRVO may have been causing visual symptoms is probably much longer. Our study analysed retinal gene expression levels of these cytokines in the acute early phase that would have been missed by these studies on humans. It appears that VEGF upregulation is delayed, and we have previously shown significant intraretinal VEGF upregulation after BRVO at 11 weeks (McAllister et al. 2009).

In the present study, expression of SDF-1 (CXCL12) was reduced at 2 days post occlusion, which may indicate the loss of secreting cells to apoptosis. The role of SDF-1 in the repair of damaged tissues including the retina has been previously investigated (Brooks et al. 2004). It has been shown to play a major role in proliferative retinopathies and is upregulated in the vitreous in eyes with ocular neovascularisation secondary to diabetic retinopathy and retinal venous occlusive (RVO) disease. In this previous study, elevated vitreous levels of SDF-1 were only found in those eyes with neovascularization, while the levels of SDF-1 were similar to that of control eyes in conditions without intraocular neovascularisation (Ki et al. 2007). In our study at 2, 6 and 10 days SDF-1 was not significantly different to normal retinas but was upregulated at 20 days suggesting this cytokine may have a role in BRVO with disease progression and possibly induced by VEGF or with the onset of intraretinal vascular remodelling (Salvucci et al. 2002). SDF-1 is thought to act in conjunction with VEGF in promoting angiogenesis by recruiting haematopoietic stem cells (Grunewald et al. 2006). 
Kaneda et al. (Kaneda et al. 2011) analysed the cytokine levels in aqueous humour in patients at several months after the onset of BRVO and showed both IL- 6 and -8 were significantly upregulated. IL-8 is an inflammatory chemokine that is upregulated in the acute phase of an ischaemic injury. It is implicated in the recruitment of inflammatory cells including neutrophils and macrophages through CXCR2 (Interleukin 8 receptor $\beta$ ) and stimulates VEGF expression (Martin, Galisteo, and Gutkind 2009; Boisvert et al. 1998; Hristov et al. 2007; Liehn, Schober, and Weber 2004). IL-8 is the most significantly associated cytokine implicated with tissue damage parameters in BRVO (Kaneda et al. 2011). IL-8 is neurotoxic (Thirumangalakudi et al. 2007) and its overproduction could lead to cell death. It precedes and controls the expression of VEGF in endothelial cells. In our study IL-8 mRNA expression was significantly upregulated at 2 and 10 days after BRVO and also remained elevated over the duration of the study to 20 days. In our study VEGF expression was only seen to be significantly upregulated at 6 days although we have previously shown it to be upregulated later and as IL-8 precedes VEGF upregulation, this would be consistent. It has been suggested that IL-8 is the main inflammatory factor involved in MO associated with BRVO (Noma et al. 2014) and has been correlated with central macular thickness and also with the severity of retinal ischaemia.

Evidence from experimental studies of intraretinal cytokine levels at known time points in retinal models similar to that of humans is lacking. Experimental studies with young animals may not replicate exactly the changes seen in elderly arteriosclerotic humans and acute studies such as this do not replicate the rate of intra retinal changes. Pigs, especially young ones may have more aggressive healing and vascular remodelling responses compared to that of humans. Alshareef et al. (Alshareef et al. 2016) demonstrated a significant reduction in ganglion cell-inner plexiform layer thickness regardless of the duration of BRVO (two groups of less and more than 3 months respectively) indicating generalised neuronal 
degeneration in eyes with BRVO remains a significant but yet unaddressed issue and models such as this are useful to explore possible mechanisms.

This study differs from several other studies in that the levels of cytokine expression in the retina were analysed as opposed to that in the aqueous or vitreous which may not reflect the actual intraretinal levels. Cytokines are likely to be more concentrated in the area of the lesion and there may be different rates at which they diffuse across the ILM in addition to any binding to extracellular matrix along its path. Furthermore, most of these studies have been performed on patients with chronic BRVOs with different durations and extent of involvement. Consequently, the levels of the cytokine milieu may differ one from another depending on the time of onset of the disease and its severity. Therefore, to establish the choice of the appropriate treatment, at the appropriate times based on these previous findings would be challenging. Current treatment options for BRVO include laser photocoagulation, intravitreal steroids and intravitreal VEGF antibodies. The effectiveness of macular grid laser is minimal, steroids are effective in the short term and whilst VEGF antibodies have proven to be more successful this does require frequent injections for extensive periods (Heier et al. 2012). VEGF is however a physiological factor that is essential for the preservation of neurons (Nishijima et al. 2007). In the acute phase of BRVO when it appears that the likelihood of neuronal damage is highest, the possibility exists, at least in this acute experimental model, that anti-VEGF therapy may potentially exacerbate this. In patients with RVO receiving VEGF inhibitors, OCT studies have shown thinning of the nerve fibre layer and inner retina, despite resolution of the MO (Klein et al. 2008; Lima et al. 2011; Alshareef et al. 2016) . The pathogenesis of this neural damage is probably multifactorial with hypoxia and induced cytokine dysregulation all potentially involved which is not addressed by current treatments. Any potential role that VEGF antagonists may have in this remains at this stage theoretic. Whilst these advances in treatment for BRVO represent a major advance, 
restoration of vision is often incomplete despite the MO eventually resolving (Heier et al. 2012).

Evidence from experimental studies of intraretinal cytokine levels in RVOs at known time points in retinal models similar to that of humans is lacking and to the best of our knowledge this has not been previously investigated in the pig model. Previous studies on RVOs have been performed on rodents (Rehak et al. 2011; Rehak et al. 2009; Ebneter et al. 2015) and SDF-1 and IL-8 have not been investigated in these studies. There was some variation in our present study in the early phase compared to these previous studies and these may be attributed to, firstly, a difference in the animal species (pigs vs rodents) as a range of histological and functional differences exist between individual species and several antibodies which labelled the same cell types in pig and human retina have shown different specificity in the mouse (Guduric-Fuchs et al. 2009). Secondly, there was a difference in the method of thrombus induction used in the rat model (Rehak et al. 2011) where sodium fluorescein instead of Rose Bengal was used and thirdly, the severity and extent of the blockage may differ particularly as a result of the extreme difference in rodents such as in the size of the eye being much smaller and the large intraocular lens in relation to the laser beam, all of which may reflect varied outcomes in the intraretinal changes.

This present study indicates that the responses in the acute phase of BRVO include inflammation as seen by the upregulation of inflammatory cytokines and breakdown of osmohomeostasis by the dislocation of Ki 4.1 water channel. Apoptosis and inner retinal damage appear to occur in the early acute stages as demonstrated in this study. This study does have some limitations as the effects of the laser used to induce the BRVO may in itself had some possible effect on intraretinal cytokine levels outside of the area of direct injury. In conclusion whilst this acute model of BRVO does not exactly replicate the changes that occur in a human with this condition it is of value in understanding the neuronal and 
intraretinal cytokine changes occurring in the early stages of this condition as the time from the initiation of the occlusive event is known. This photothrombotic model produces an occlusion that is acute and relatively more severe than the slow and progressive occlusion and retinal changes seen in most patients with a BRVO (Hayreh et al. 2001). It does demonstrate that neuronal degeneration and alteration in homeostasis occurs early in this condition and that there is a potential for additional treatments in this early phase that may be able to reverse apoptosis in those cells that are less severely affected. Neuroprotective treatments and targeting of dislocated water channels may be advantageous in attenuating the progression of BRVO induced neural damage.

VEGF is not upregulated immediately in this model and the theoretic possibility exists that early treatment with antagonists to this cytokine which does in itself have neuroprotective capabilities before it is fully upregulated may be counterproductive. As the pathogenesis of BRVO clinically differs significantly from this experimental model this would not affect current management, however further investigation into potentially effective neuroprotective agents is required.

Acknowledgments

The authors thank Slavica Pervan for tissue sectioning and Shang-Chih Chen for western blot analysis for validation of antibodies. 
References

Abu-El-Asrar, A. M., L. Dralands, L. Missotten, I. A. Al-Jadaan, and K. Geboes. 2004. 'Expression of apoptosis markers in the retinas of human subjects with diabetes', Invest Ophthalmol Vis Sci, 45: 2760-6.

Alshareef, R. A., G. Barteselli, Q. You, A. Goud, A. Jabeen, H. L. Rao, A. Jabeen, and J. Chhablani. 2016. 'In vivo evaluation of retinal ganglion cells degeneration in eyes with branch retinal vein occlusion', Br J Ophthalmol, 100: 1506-10.

Baglivo, E., A. Dosso, and C. Pournaras. 1997. 'Thrombus and branch retinal vein occlusion', Graefes Arch Clin Exp Ophthalmol, 235: 10-3.

Barber, A. J., E. Lieth, S. A. Khin, D. A. Antonetti, A. G. Buchanan, and T. W. Gardner. 1998. 'Neural apoptosis in the retina during experimental and human diabetes. Early onset and effect of insulin', J Clin Invest, 102: 783-91.

Boisvert, W. A., R. Santiago, L. K. Curtiss, and R. A. Terkeltaub. 1998. 'A leukocyte homologue of the IL- 8 receptor CXCR-2 mediates the accumulation of macrophages in atherosclerotic lesions of LDL receptor-deficient mice', J Clin Invest, 101: 353-63.

Bringmann, A., I. Iandiev, T. Pannicke, A. Wurm, M. Hollborn, P. Wiedemann, N. N. Osborne, and A. Reichenbach. 2009. 'Cellular signaling and factors involved in Muller cell gliosis: neuroprotective and detrimental effects', Prog Retin Eye Res, 28: 423-51.

Bringmann, A., T. Pannicke, J. Grosche, M. Francke, P. Wiedemann, S.N. Skatchkov, N.N. Osborne, and A. Reichenbach. 2006. 'Muller cells in the healthy and diseased retina', Prog. Retin. Eye Res, 25: 397-424.

Brooks, H.L., Jr., Caballero S Jr, C.K. Newell, R.L. Steinmetz, D. Watson, M.S. Segal, J.K. Harrison, E.W. Scott, and M.B. Grant. 2004. 'Vitreous levels of vascular endothelial growth factor and stromal-derived factor 1 in patients with diabetic retinopathy and cystoid macular edema before and after intraocular injection of triamcinolone', Arch. Ophthalmol, 122: 1801-07.

Campochiaro, P. A., W. L. Clark, D. S. Boyer, J. S. Heier, D. M. Brown, R. Vitti, H. Kazmi, A. J. Berliner, K. Erickson, K. W. Chu, Y. Soo, Y. Cheng, and J. A. Haller. 2015. 'Intravitreal aflibercept for macular edema following branch retinal vein occlusion: the 24-week results of the VIBRANT study', Ophthalmology, 122: 538-44.

Campochiaro, P.A., J.S. Heier, L. Feiner, S. Gray, N. Saroj, A.C. Rundle, W.Y. Murahashi, and R.G. Rubio. 2010. 'Ranibizumab for macular edema following branch retinal vein occlusion: six-month primary end point results of a phase III study', Ophthalmology, 117: 1102-12.

Crowley, L. C., B. J. Marfell, A. P. Scott, J. A. Boughaba, G. Chojnowski, M. E. Christensen, and N. J. Waterhouse. 2016. 'Dead Cert: Measuring Cell Death', Cold Spring Harb Protoc, 2016: pdb top070318.

Crowley, L. C., B. J. Marfell, and N. J. Waterhouse. 2016. 'Detection of DNA Fragmentation in Apoptotic Cells by TUNEL', Cold Spring Harb Protoc, 2016: pdb prot087221.

Diez-Roux, G., and R. A. Lang. 1997. 'Macrophages induce apoptosis in normal cells in vivo', Development, 124: 3633-8.

Donati, G., A. Kapetanios, M. Dubois-Dauphin, and C. J. Pournaras. 2008. 'Caspase-related apoptosis in chronic ischaemic microangiopathy following experimental vein occlusion in mini-pigs', Acta Ophthalmol, 86: 302-6.

Ebneter, A., C. Agca, C. Dysli, and M. S. Zinkernagel. 2015. 'Investigation of retinal morphology alterations using spectral domain optical coherence tomography in a mouse model of retinal branch and central retinal vein occlusion', PLoS One, 10: e0119046. 
Eisenfeld, A.J., A.H. Bunt-Milam, and P.V. Sarthy. 1984. 'Muller cell expression of glial fibrillary acidic protein after genetic and experimental photoreceptor degeneration in the rat retina', Invest Ophthalmol. Vis. Sci, 25: 1321-28.

Elmore, S. 2007. 'Apoptosis: a review of programmed cell death', Toxicol Pathol, 35: 495516.

Fedchenko, N., and J. Reifenrath. 2014. 'Different approaches for interpretation and reporting of immunohistochemistry analysis results in the bone tissue - a review', Diagn Pathol, 9: 221.

Frangieh, G. T., W. R. Green, E. Barraquer-Somers, and D. Finkelstein. 1982. 'Histopathologic study of nine branch retinal vein occlusions', Arch Ophthalmol, 100: 1132-40.

Funatsu, H., H. Noma, T. Mimura, and S. Eguchi. 2012. 'Vitreous inflammatory factors and macular oedema', Br J Ophthalmol, 96: 302-4.

Funatsu, H., H. Yamashita, E. Shimizu, R. Kojima, and S. Hori. 2001. 'Relationship between vascular endothelial growth factor and interleukin-6 in diabetic retinopathy', Retina, 21: 469-77.

Funk, M., K. Kriechbaum, F. Prager, T. Benesch, M. Georgopoulos, G. J. Zlabinger, and U. Schmidt-Erfurth. 2009. 'Intraocular concentrations of growth factors and cytokines in retinal vein occlusion and the effect of therapy with bevacizumab', Invest Ophthalmol Vis Sci, 50: 1025-32.

Grunewald, M., I. Avraham, Y. Dor, E. Bachar-Lustig, A. Itin, S. Jung, S. Chimenti, L. Landsman, R. Abramovitch, and E. Keshet. 2006. 'VEGF-induced adult neovascularization: recruitment, retention, and role of accessory cells', Cell, 124: 17589.

Guduric-Fuchs, J., L. J. Ringland, P. Gu, M. Dellett, D. B. Archer, and T. Cogliati. 2009. 'Immunohistochemical study of pig retinal development', Mol Vis, 15: 1915-28.

Hayreh, S.S., B. Zimmerman, M.J. McCarthy, and P. Podhajsky. 2001. 'Systemic diseases associated with various types of retinal vein occlusion', Am. J. Ophthalmol, 131: 6177.

Heier, J. S., P. A. Campochiaro, L. Yau, Z. Li, N. Saroj, R. G. Rubio, and P. Lai. 2012. 'Ranibizumab for macular edema due to retinal vein occlusions: long-term follow-up in the HORIZON trial', Ophthalmology, 119: 802-9.

Hristov, M., A. Zernecke, K. Bidzhekov, E. A. Liehn, E. Shagdarsuren, A. Ludwig, and C. Weber. 2007. 'Importance of CXC chemokine receptor 2 in the homing of human peripheral blood endothelial progenitor cells to sites of arterial injury', Circ Res, 100: 590-7.

Huang, H., J. K. Gandhi, X. Zhong, Y. Wei, J. Gong, E. J. Duh, and S. A. Vinores. 2011. 'TNFalpha is required for late BRB breakdown in diabetic retinopathy, and its inhibition prevents leukostasis and protects vessels and neurons from apoptosis', Invest Ophthalmol Vis Sci, 52: 1336-44.

Joo, C. K., J. S. Choi, H. W. Ko, K. Y. Park, S. Sohn, M. H. Chun, Y. J. Oh, and B. J. Gwag. 1999. 'Necrosis and apoptosis after retinal ischemia: involvement of NMDA-mediated excitotoxicity and p53', Invest Ophthalmol Vis Sci, 40: 713-20.

Kaneda, S., D. Miyazaki, S. Sasaki, K. Yakura, Y. Terasaka, K. Miyake, Y. Ikeda, T. Funakoshi, T. Baba, A. Yamasaki, and Y. Inoue. 2011. 'Multivariate analyses of inflammatory cytokines in eyes with branch retinal vein occlusion: relationships to bevacizumab treatment', Invest Ophthalmol. Vis. Sci, 52: 2982-88.

Kerr, J. F., A. H. Wyllie, and A. R. Currie. 1972. 'Apoptosis: a basic biological phenomenon with wide-ranging implications in tissue kinetics', Br J Cancer, 26: 239-57. 
Khandelwal, P. J., A. M. Herman, and C. E. Moussa. 2011. 'Inflammation in the early stages of neurodegenerative pathology', J Neuroimmunol, 238: 1-11.

Khayat, M., N. Lois, M. Williams, and A. W. Stitt. 2017. 'Animal Models of Retinal Vein Occlusion', Invest Ophthalmol Vis Sci, 58: 6175-92.

Ki, I., N. Arimura, Y. Noda, K. Yamakiri, N. Doi, T. Hashiguchi, I. Maruyama, M. Shimura, and T. Sakamoto. 2007. 'Stromal-derived factor-1 and inflammatory cytokines in retinal vein occlusion', Curr. Eye Res, 32: 1065-72.

Kim, C. S., K. S. Shin, H. J. Lee, Y. J. Jo, and J. Y. Kim. 2014. 'Sectoral retinal nerve fiber layer thinning in branch retinal vein occlusion', Retina, 34: 525-30.

Kim, I., A. M. Ryan, R. Rohan, S. Amano, S. Agular, J. W. Miller, and A. P. Adamis. 1999. 'Constitutive expression of VEGF, VEGFR-1, and VEGFR-2 in normal eyes', Invest Ophthalmol Vis Sci, 40: 2115-21.

Klein, R., B.E. Klein, S.E. Moss, and S.M. Meuer. 2000. 'The epidemiology of retinal vein occlusion: the Beaver Dam Eye Study', Trans. Am. Ophthalmol. Soc, 98: 133-41.

Klein, R., S.E. Moss, S.M. Meuer, and B.E. Klein. 2008. 'The 15-year cumulative incidence of retinal vein occlusion: the Beaver Dam Eye Study', Arch. Ophthalmol, 126: 51318.

Kovacs, Z., K. Ikezaki, K. Samoto, T. Inamura, and M. Fukui. 1996. 'VEGF and flt. Expression time kinetics in rat brain infarct', Stroke, 27: 1865-72; discussion 72-3.

Kumar, B., D. Y. Yu, W. H. Morgan, C. J. Barry, I. J. Constable, and I. L. McAllister. 1998. 'The distribution of angioarchitectural changes within the vicinity of the arteriovenous crossing in branch retinal vein occlusion', Ophthalmology, 105: 424-7.

Labat-gest, V., and S. Tomasi. 2013. 'Photothrombotic ischemia: a minimally invasive and reproducible photochemical cortical lesion model for mouse stroke studies', $J$ Vis Exp.

Lee, W. J., M. H. Kang, M. Seong, and H. Y. Cho. 2012. 'Comparison of aqueous concentrations of angiogenic and inflammatory cytokines in diabetic macular oedema and macular oedema due to branch retinal vein occlusion', Br J Ophthalmol, 96: 142630.

Liehn, E. A., A. Schober, and C. Weber. 2004. 'Blockade of keratinocyte-derived chemokine inhibits endothelial recovery and enhances plaque formation after arterial injury in ApoE-deficient mice', Arterioscler Thromb Vasc Biol, 24: 1891-6.

Lim, J. W. 2011. 'Intravitreal bevacizumab and cytokine levels in major and macular branch retinal vein occlusion', Ophthalmologica, 225: 150-4.

Lima, V. C., L. Yeung, L. C. Castro, G. Landa, and R. B. Rosen. 2011. 'Correlation between spectral domain optical coherence tomography findings and visual outcomes in central retinal vein occlusion', Clin Ophthalmol, 5: 299-305.

Livak, K. J., and T. D. Schmittgen. 2001. 'Analysis of relative gene expression data using real-time quantitative PCR and the 2(-Delta Delta C(T)) Method', Methods, 25: 402-8.

Lobo, C.L., R.C. Bernardes, and J.G. Cunha-Vaz. 2000. 'Alterations of the blood-retinal barrier and retinal thickness in preclinical retinopathy in subjects with type 2 diabetes', Arch. Ophthalmol, 118: 1364-69.

Martin, D., R. Galisteo, and J. S. Gutkind. 2009. 'CXCL8/IL8 stimulates vascular endothelial growth factor (VEGF) expression and the autocrine activation of VEGFR2 in endothelial cells by activating NFkappaB through the CBM (Carma3/Bc110/Malt1) complex', J Biol Chem, 284: 6038-42.

McAllister, I. L., S. Vijayasekaran, S. D. Chen, and D. Y. Yu. 2009. 'Effect of triamcinolone acetonide on vascular endothelial growth factor and occludin levels in branch retinal vein occlusion', Am J Ophthalmol, 147: 838-46, 46 e1-2.

McAllister, I. L., S. Vijayasekaran, W. Xia, and D. Y. Yu. 2013. 'Evaluation of the ability of a photocoagulator to rupture the retinal vein and Bruch's membrane for potential vein 
bypass in retinal vein occlusion', Ophthalmic Surg Lasers Imaging Retina, 44: 26873.

McAllister, I. L., S. Vijayasekaran, and D. Y. Yu. 2013. 'Intravitreal tenecteplase (metalyse) for acute management of retinal vein occlusions', Invest Ophthalmol Vis Sci, 54: 4910-8.

Mitchell, P., W. Smith, and A. Chang. 1996. 'Prevalence and associations of retinal vein occlusion in Australia. The Blue Mountains Eye Study', Arch. Ophthalmol, 114: 1243-47.

Nishijima, K., Y. S. Ng, L. Zhong, J. Bradley, W. Schubert, N. Jo, J. Akita, S. J. Samuelsson, G. S. Robinson, A. P. Adamis, and D. T. Shima. 2007. 'Vascular endothelial growth factor-A is a survival factor for retinal neurons and a critical neuroprotectant during the adaptive response to ischemic injury', Am J pathol, 171: 53-67.

Noma, H., H. Funatsu, T. Mimura, and K. Shimada. 2010. 'Increase of aqueous inflammatory factors in macular edema with branch retinal vein occlusion: a case control study', $J$ Inflamm (Lond), 7: 44.

Noma, H., H. Funatsu, M. Yamasaki, H. Tsukamoto, T. Mimura, T. Sone, T. Hirayama, H. Tamura, H. Yamashita, A. Minamoto, and H. K. Mishima. 2008. 'Aqueous humour levels of cytokines are correlated to vitreous levels and severity of macular oedema in branch retinal vein occlusion', Eye (Lond), 22: 42-8.

Noma, H., H. Funatsu, M. Yamasaki, H. Tsukamoto, T. Mimura, T. Sone, K. Jian, I. Sakamoto, K. Nakano, H. Yamashita, A. Minamoto, and H. K. Mishima. 2005. 'Pathogenesis of macular edema with branch retinal vein occlusion and intraocular levels of vascular endothelial growth factor and interleukin-6', Am J Ophthalmol, 140: 256-61.

Noma, H., T. Mimura, and S. Eguchi. 2013. 'Association of inflammatory factors with macular edema in branch retinal vein occlusion', JAMA Ophthalmol, 131: 160-5.

Noma, H., T. Mimura, K. Yasuda, and M. Shimura. 2014. 'Role of soluble vascular endothelial growth factor receptors-1 and -2, their ligands, and other factors in branch retinal vein occlusion with macular edema', Invest Ophthalmol Vis Sci, 55: 3878-85.

Noma, H., A. Minamoto, H. Funatsu, H. Tsukamoto, K. Nakano, H. Yamashita, and H.K. Mishima. 2006. 'Intravitreal levels of vascular endothelial growth factor and interleukin-6 are correlated with macular edema in branch retinal vein occlusion', Graefes Arch. Clin. Exp. Ophthalmol, 244: 309-15.

Okunuki, Y., Y. Usui, N. Katai, T. Kezuka, M. Takeuchi, H. Goto, and Y. Wakabayashi. 2011. 'Relation of intraocular concentrations of inflammatory factors and improvement of macular edema after vitrectomy in branch retinal vein occlusion', $\mathrm{Am}$ J Ophthalmol, 151: 610-16 e1.

Pannicke, T., I. Iandiev, O. Uckermann, B. Biedermann, F. Kutzera, P. Wiedemann, H. Wolburg, A. Reichenbach, and A. Bringmann. 2004. 'A potassium channel-linked mechanism of glial cell swelling in the postischemic retina', Mol. Cell Neurosci, 26: 493-502.

Puwarawuttipanit, W., A. D. Bragg, D. S. Frydenlund, M. N. Mylonakou, E. A. Nagelhus, M. F. Peters, N. Kotchabhakdi, M. E. Adams, S. C. Froehner, F. M. Haug, O. P. Ottersen, and M. Amiry-Moghaddam. 2006. 'Differential effect of alpha-syntrophin knockout on aquaporin-4 and Kir4.1 expression in retinal macroglial cells in mice', Neuroscience, 137: 165-75.

Rehak, M., F. Drechsler, P. Koferl, M. Hollborn, P. Wiedemann, A. Bringmann, and L. Kohen. 2011. 'Effects of intravitreal triamcinolone acetonide on retinal gene expression in a rat model of central retinal vein occlusion', Graefes Arch Clin Exp Ophthalmol, 249: 1175-83. 
Rehak, M., M. Hollborn, I. Iandiev, T. Pannicke, A. Karl, A. Wurm, L. Kohen, A. Reichenbach, P. Wiedemann, and A. Bringmann. 2009. 'Retinal gene expression and Muller cell responses after branch retinal vein occlusion in the rat', Invest Ophthalmol. Vis. Sci, 50: 2359-67.

Rogers, S. L., R. L. McIntosh, L. Lim, P. Mitchell, N. Cheung, J. W. Kowalski, H. P. Nguyen, J. J. Wang, and T. Y. Wong. 2010. 'Natural history of branch retinal vein occlusion: an evidence-based systematic review', Ophthalmology, 117: 1094-101 e5.

Rogers, S., R.L. McIntosh, N. Cheung, L. Lim, J.J. Wang, P. Mitchell, J.W. Kowalski, H. Nguyen, and T.Y. Wong. 2010. 'The prevalence of retinal vein occlusion: pooled data from population studies from the United States, Europe, Asia, and Australia', Ophthalmology, 117: 313-19.

Salvucci, O., L. Yao, S. Villalba, A. Sajewicz, S. Pittaluga, and G. Tosato. 2002. 'Regulation of endothelial cell branching morphogenesis by endogenous chemokine stromalderived factor-1', Blood, 99: 2703-11.

Sapieha, P., D. Hamel, Z. Shao, J. C. Rivera, K. Zaniolo, J. S. Joyal, and S. Chemtob. 2010. 'Proliferative retinopathies: angiogenesis that blinds', Int J Biochem Cell Biol, 42: 512.

Silva, R. M., J. R. Faria de Abreu, and J. G. Cunha-Vaz. 1995. 'Blood-retina barrier in acute retinal branch vein occlusion', Graefes Arch Clin Exp Ophthalmol, 233: 721-6.

The Branch Vein Occlusion Study Group. 1984. 'Argon laser photocoagulation for macular edema in branch vein occlusion', Am J Ophthalmol, 98: 271-82.

Thirumangalakudi, L., L. Yin, H. V. Rao, and P. Grammas. 2007. 'IL-8 induces expression of matrix metalloproteinases, cell cycle and pro-apoptotic proteins, and cell death in cultured neurons', J Alzheimers Dis, 11: 305-11.

Vinores, S. A., N. L. Derevjanik, A. Shi, M. A. Vinores, D. A. Klein, and J. A. WhittumHudson. 2001. 'Vascular endothelial growth factor (VEGF), transforming growth factor-beta (TGFbeta), and interleukin-6 (IL-6) in experimental herpesvirus retinopathy: association with inflammation and viral infection', Histol Histopathol, 16: 1061-71.

Wong, T. Y., and I. U. Scott. 2010. 'Clinical practice. Retinal-vein occlusion', N Engl J Med, 363: 2135-44.

Zille, M., T. D. Farr, I. Przesdzing, J. Muller, C. Sommer, U. Dirnagl, and A. Wunder. 2012. 'Visualizing cell death in experimental focal cerebral ischemia: promises, problems, and perspectives', J Cereb Blood Flow Metab, 32: 213-31. 


\section{Legends}

\section{Figure 1: Photothrombotic branch retinal vein Occlusion.}

A: Macroscopic view of the eyecup of a BRVO retina at 1 weeks showing attenuation of flow of blood (dotted circle) towards the optic disc (OD) at the laser burn site.

B: Light micrograph of retina at 1 week in which BRVO was attempted showing the lumen of the vein occupied almost completely by a thrombus packed with red blood cells clumped together. A macrophage is seen close to the occluded vein (red arrow). Scale bar $=30 \mu \mathrm{m}$.

C: Transmission electron micrograph of a BRVO showing an area of the thrombus composed of packed stagnant red blood cells adjacent to the wall of a retinal vein with endothelial cell. Scale bar $=0.3 \mu \mathrm{m}$.

\section{Figure 2: TUNEL labelling.}

TUNEL staining of normal retina (A) showing an absence of TUNEL positive cells. Blood cells show yellow autofluoresecence, (C) at 2 days several cells in the ganglion cell layer (GCL) and the inner nuclear (INL) show staining of apoptotic cells (arrow) and (E) scarce staining at 6 days after a BRVO was created. Positive control $(G)$ incubated with Dnase I to damage nuclei showed intense staining (arrow) and negative control (H) incubated with label solution only showed an absence of staining. Hoechst treated retina (B, D and F) showing bright nuclear staining of all cells of normal retina, at 2 and 6 days post occlusion respectively. ILM: Inner limiting membrane. Scale bar $=17 \mu \mathrm{m}$.

Figure 3. Graph showing percentage of dying TUNEL positive cells.

Graph demonstrating percentage of TUNEL positive cell counts significantly higher $(*)$ at 2 days in the ganglion cell layer (GCL) compared to the normal retina and at 6,10 and 20 
days, and in the inner nuclear layer (INL) compared to normal retina and at 10 days respectively after a BRVO was attempted.

\section{Figure 4. Graph showing percentage of pyknotic nuclei.}

Graph demonstrating pyknotic celll counts significantly higher at 2 days $(*)$ in the ganglion cell layer (GCL) compared to normal retina and retina at 6 days and in the inner nuclear layer (INL) at 2 days compared to normal retina and retina at 6,10 and 20 respectively after a BRVO was attempted.

\section{Figure 5: Histology - Light Microscopy.}

Light micrographs of normal retina $\mathbf{A}$, showing healthy retinal structure with ganglion cells with nuclei and nucleolus in the ganglion cell layer (GCL), normal looking inner nuclear (INL) and outer nuclear layer (ONL). B, retina 2 days after BRVO was attempted retina showing vacuoles $\left(^{*}\right)$ in the GCL and INL, C, 6 days after BRVO was attempted displaying vacuoles (*) in the GCL and INL, pyknosis in the INL and both INL and ONL showing displacement of their nuclei. D, retina 10 days after BRVO was attempted displaying more severe damage with vacuoles $(*)$ in the GCL and INL in which pyknotic cells are seen with reduced layers of nuclei. E, retina 20 days after BRVO was attempted displaying vacuoles (*) in the GCL and INL in which pyknotic cells are seen. ONL shows mild displacement of nuclei. Scale bar $=11 \mu \mathrm{m}$.

Figure 6: Histology - Transmission Electron Microscopy. 
Transmission electron micrographs of a retina 2 days after BRVO was attempted showing $\mathbf{A}$, a cell in the ganglion cell layer with apoptotic changes in the nuclei $(\mathrm{N})$ including chromatin in the nuclear periphery, organelles still intact but with condensation of the cystosol, $\mathbf{B}$, cells in the inner nuclear layer showing changes in the nuclei $(\mathrm{N})$, vacuoles $\left({ }^{*}\right)$ and myelin debris, scale bar $=0.8 \mu \mathrm{m}: \quad \mathbf{C}, 20$ days after BRVO was attempted showing inner limiting membrane composed of reduced Muller end-feet (E) membranous debris and an astrocyte with nucleous $(\mathrm{N})$ in the process of degeneration showing vacuolation $(*)$ and debris of its soma. Vacuoles are also seen among Muller cell fibres (MF) containing swollen mitochondria $(\mathrm{M})$, scale bar $=5 \mu \mathrm{m}$ : D, Muller cell fibres interior appear disorganised and appear to have lost the regular tubular structure. Vacuoles and mitochondrial swelling is also seen, scale bar $=3 \mu \mathrm{m}$ : E, Degenerating Muller cells (MC) with extending fibres containing swollen mitochondria and a loss of cell organelles are seen: F, Inner nuclear layer showing a bipolar cell (BP), adjoining vacant spaces $\left(^{*}\right)$ that may have been occupied by cells and a Muller cell undergoing degenerative changes depicted by vacuoles in its soma. Scale bar $=5$ $\mu \mathrm{m}$.

\section{Figure 7: RT-qPCR}

Graph of RT-qPCR demonstrating the relative expression levels of the pig retinal genes (normalised against the housekeeping gene glyceraldehyde-3-phosphate dehydrogenase) for intermediate filament glial fibrillary acidic protein (GFAP), channel proteins, aquaporin 4 (AQP4), inward rectifier potassium channel $10\left(\mathrm{~K}_{\mathrm{ir}} 4.1\right)$ and inflammatory cytokines vascular endothelial growth factor (VEGF), stromal derived growth factor-1 $\alpha$ (SDF-1), interleukin 6 (IL-6), interleukin 8 (IL-8) in BRVO and normal retinas. * indicates statistical significance (p $<0.05)$ compared to controls.

Figure 8: Immunohistochemistry of GFAP, AQP4 and Kir 4.1. 
Immunolocalisation (arrow) of GFAP (A, normal; B, 2 days; C, 6 days; D, 10 days; E, 20 days; F, negative control), AQP4 (G, normal; H, 2 days; I, 6 days; J, 10 days; K, 20 days; $\mathbf{L}$, negative control) and $\mathrm{K}_{\mathrm{ir}}$ 4.1. (M, normal; $\mathbf{N}, 2$ days; $\mathbf{O}, 6$ days; $\mathbf{P}, 10$ days; $\mathbf{Q}, 20$ days; $\mathbf{R}$, negative control) in the retinas of normal and eyes enucleated at 2, 6, 10 and 20 days after a BRVO was created.

GFAP is seen localised in the astrocytes in retina of normal (A) and BRVO retinas at $10(\mathbf{C})$ and 20 (D) days respectively, Muller cells show staining in the retinas with BRVO at all time points.

AQP4 staining is seen predominantly in the inner limiting membrane and in the perivascular regions in the normal and BRVO retinas at all time points.

$\mathrm{K}_{\mathrm{ir}} 4.1$ showing intense staining in all the layers and in the Muller fibres of the normal retina and weak staining in the BRVO retinas at all other time points.

Autofluorescence $\left(^{*}\right)$ of inner segments and blood cells is seen in most of the retinas including the negative control.

ILM, Inner limiting membrane; ONL, outer nuclear layer: Scale bar $=30 \mu \mathrm{m}$.

Figure 9: Immunohistochemistry of VEGF and SDF-1.

Immunolocalisation (arrow) of VEGF (A, normal; B, 2 days; C, 6 days; D 10 days; E, 20 days; F, negative control) ,SDF -1 (G, normal; H, 2 days; I, 6 days; J, 10 days; $\mathbf{K}, 20$ days; $\mathbf{L}$, negative control) in the retinas of normal and eyes enucleated at 2, 6,10 and 20 days after a BRVO was created.

VEGF and: SDF-1 showing diffuse staining predominantly in the inner retinal layers of normal and treated retinas.

ILM, Inner limiting membrane; ONL, outer nuclear layer. Scale bar $=33 \mu \mathrm{m}$. 


\section{Figure 10: Immunohistochemistry of IL-6 and IL-8.}

Immunolocalisation (arrow) of IL-6 A, normal; B, 2 days; C, 6 days; D, 10 days; E, 20 days; F, negative control) and IL-8 (G, normal; H, 2 days; I, 6 days; J, 10 days; K, 20 days; $\mathbf{L}$, negative control) in the retinas of normal and eyes enucleated at 2, 6, 10 and 20 days after a BRVO was created.

Autofluorescence $(*)$ of inner segments is seen in most of the retinas including the negative control.

IL-6 is seen in the inner retinal layers. IL-8 is seen in the inner retinal layers.

ILM, Inner limiting membrane; ONL, outer nuclear layer. Scale bar $=33 \mu \mathrm{m}$. 


\section{Highlights}

- Neuronal damage and changes in cytokines and proteins in acute BRVO was investigated

- Alterations in mRNA levels of GFAP, AQP4, Kir4.1, VEGF, SDF-1 IL-6 and -8 and neurodegeneration were significant

- Development of neuroprotective treatment strategies are proposed 


\title{
Neuronal Degeneration and Associated Alterations in Cytokine and Protein in an Experimental Branch Retinal Venous Occlusion Model
}

Word count: 7745

Figures: 10

Authors:

\author{
Ian L. McAllister ${ }^{1,2,3}$ \\ Sarojini Vijayasekaran ${ }^{1,2}$ \\ Dan Zhang ${ }^{1,2}$ \\ Samuel McLenachan ${ }^{1,2}$ \\ Fred Kuanfu Chen ${ }^{1,2,3}$ \\ Dao-Yi $\mathrm{Yu}^{1,2}$
}

${ }^{1}$ Centre for Ophthalmology and Visual Science, The University of Western Australia, Perth, Australia.

${ }^{2}$ Lions Eye Institute, The University of Western Australia, Perth, Australia

${ }^{3}$ Department of Ophthalmology, Royal Perth Hospital, Perth, Australia

Corresponding author:

Professor I L McAllister

Lions Eye Institute,

Centre for Ophthalmology and Visual Science,

The University of Western Australia,

Nedlands, WA 6009,

Australia.

E-mail: ianmcallister@lei.org.au

Phone: 6189381870

Fax: 61893810766

Grant support was provided by the National Health and Medical Research Council of Australia 


\section{Abstract}

The mechanisms of neuronal degeneration and associated acute alterations in intraretinal cytokine and protein levels remain poorly understood in variable ischaemic retinopathies such as in branch retinal vein occlusion (BRVO). Herein we investigate neuronal damage and alterations in retinal cytokines and proteins in a pig model of acute BRVO. Twelve pigs had a BRVO induced photothrombotically in both eyes. Three pigs (6 eyes) each at 2, 6, 10 and 20 days were sacrificed together with an additional 3 control (6 eyes), enucleated, retinas dissected and processed. Apoptosis in the inner retina was determined by terminal deoxyynuclotidyl transferase mediated dUTP nick end labelling (TUNEL) and histology. Expression of glial acidic fibrillary protein (GFAP), aquaporin-4 (AQP4), inward rectifier potassium channel 10 protein $\left(\mathrm{K}_{\mathrm{ir}} 4.1\right)$ encoded by KCNJ10 gene, vascular endothelial growth factor (VEGF), stromal derived growth factor-1 $\alpha$ (SDF-1) encoded by CXCL12 gene and interleukin (IL) -6 and 8 were analysed by quantitative reverse transcription polymerase chain reaction (RT-qPCR) and immunohistochemistry. TUNEL labelling showed positive nuclei in the ganglion cell layer (GCL) and the inner nuclear layer (INL) which was significantly higher at 2 days after BRVO compared to other time points $(\mathrm{p}<0.05)$. Analysis by RT-qPCR revealed that compared with controls, BRVO significantly increased mRNA expression of GFAP at 6, 10 and 20, AQP4 at 20, VEGF at 6, SDF-1 at 20 and IL-8 at 2 and 10 days respectively $(\mathrm{p}<0.05): \mathrm{K}_{\mathrm{ir}} 4.1$ at 6 , VEGF at 2 and 10, and IL-6 at 2 days were significantly decreased $(\mathrm{p}<0.05)$. This study indicates that neural cell death occurs early in this acute model and the responses include inflammation and breakdown of osmohomeostasis as evidenced by the upregulation of GFAP and IL- 8 and down regulation of $\mathrm{K}_{\mathrm{ir}} 4.1$ associated with glyotic changes. Early short term VEGF upregulation seen may be related to involvement of Muller glial cells. These findings support the development of acute therapeutic strategies aimed at preservation of retinal neural cells as part of an overall management plan for BRVO. 
Key words:

retinal vein occlusion

Neurodegeneration

Apoptosis

Cytokine 


\section{Introduction}

Retinal vein occlusion (RVO) is the second most common cause of retinal vascular blindness after diabetic retinopathy (DR) affecting approximately 16 million people worldwide (Klein et al. 2000; Mitchell, Smith, and Chang 1996; Rogers, McIntosh, Cheung, et al. 2010). Approximately 1\% of individuals under 60 years of age are affected with the prevalence increasing to $5 \%$ in those over 80 years (Mitchell, Smith, and Chang 1996). RVO is a variable ischaemic microvascular retinal disease and remains a common cause of unilateral vision loss that may affect either a branch vein or the central retinal vein (CRVO). Of all retinal vein occlusions branch retinal vein occlusion (BRVO) is the most common and accounts for $80 \%$ of all vein occlusions (Mitchell, Smith, and Chang 1996; Klein et al. 2008). Without treatment, it can lead to a sustained loss of vision with a reported final mean visual acuity of $20 / 70$ with $23 \%$ of patients having a visual acuity of $\geq 20 / 200$ ('Argon laser photocoagulation for macular edema in branch vein occlusion. The Branch Vein Occlusion Study Group' 1984; Rogers, McIntosh, Lim, et al. 2010) . The pathogenesis of BRVO has been attributed to a combination of local changes in the vein at the arterio-venous crossing including degenerative changes of the vessel wall, compression, haemorheological changes, endothelial damage and deregulation of the thrombosis-fibrinolysis balance (Baglivo, Dosso, and Pournaras 1997; Frangieh et al. 1982; Kumar et al. 1998) resulting in retinal oedema, haemorrhage and neural degeneration. Programmed cell death (apoptosis) is considered a leading cause of neural degenerative mechanism invoked in these diseases (Donati et al. 2008; Joo et al. 1999). Understanding this mechanism at the molecular level may provide deeper insights into the processes involved and may be beneficial in the development of new therapeutic strategies. 
A common pathological sequel of RVOs is macular oedema (MO) (Wong and Scott 2010), where there is extra- and intracellular fluid accumulation, culminating in neural cell damage and death. It has been demonstrated that cytokines play a major role in the pathology of these diseases (Ki et al. 2007), however, the exact sequence of cytokine upregulation after the occlusion and the effects of these on retinal cellular elements remains to be elucidated. The development of MO has been attributed to the cytokine vascular endothelial growth factor (VEGF) and nitric oxide production. In recent years, intravitreal VEGF inhibitors have revolutionised treatment for these conditions confirming that MO is strongly associated with the upregulation of this cytokine (Campochiaro et al. 2010; Campochiaro et al. 2015) that enhances blood retinal barrier (BRB) breakdown, vascular permeability and leakage (Silva, Faria de Abreu, and Cunha-Vaz 1995). However, although this treatment improves visual outcomes in the short term over previous treatments such as grid laser, vision is not completely restored ('Argon laser photocoagulation for macular edema in branch vein occlusion. The Branch Vein Occlusion Study Group' 1984; Campochiaro et al. 2010; Campochiaro et al. 2015). Whilst these inhibitors control leakage, they do not resolve neural damage by apoptosis which occurs early, is progressive and currently irreversible.

It has been proven that the apoptotic processes in cells can be reversed by DNA repair in some circumstances, (Elmore 2007; Diez-Roux and Lang 1997) as in the case of experimental diabetic mice where leukostasis, retinal cell death and vascular permeability was abrogated in the absence of TNF $\alpha$ (Huang et al. 2011). In DR, another retinal microvascular disease, loss of the nerve fibre layer seems to occur early, often when there are only minimal retinal changes, and becomes worse with increasing severity of retinopathy. Retinal ganglion cell (RGC) death can be very slow and variable in the early clinical stages where they are in a pre-apoptotic state (Abu-El-Asrar et al. 2004). Damage to the retinal neural layers are seen clinically in both branch and central RVOs with OCT studies showing 
nerve fibre layer thinning even in the absence of capillary nonperfusion (Kim et al. 2014; Lima et al. 2011). Attenuating ischaemic neural injury and targeting these vulnerable cells in the inner retina before progression to an irreversible stage at the appropriate times would be exceedingly significant. However, in order to develop applicable neuroprotective strategies, it is necessary to understand the sequence of changes controlling neural damage from its initiation at the acute phase.

In this study, we investigate the timing of apoptosis and neural degeneration in the acute post-occlusion period (2-20 days), using our well-established pig model of BRVO (McAllister et al. 2009; McAllister et al. 2013; McAllister, Vijayasekaran, and Yu 2013). We have used terminal dUTP-mediated nick end labelling (TUNEL) which labels fragmented DNA, histology including ultra-structure to assess pyknosis (early changes of nuclear shrinkage and chromatin condensation) (Kerr, Wyllie, and Currie 1972) and architectural changes that occur in this acute phase. Concurrently, we examined changes in retinal gene expression occurring in the acute phase of BRVO by quantitative reverse transcription polymerase chain reaction (RT-qPCR) targeting a panel of cytokines (VEGF, SDF-1 encoded by CXCL12 gene, IL6, IL8), membrane-associated channels (AQP4, Kir 4.1 encoded by KCNJ10 gene) and markers of gliosis (GFAP). Protein expression and localization was examined by immunostaining. These markers were chosen as they have various pathological effects including gliosis, MO, angiogenesis and inflammation in vascular retinopathies (Bringmann et al. 2006) (Sapieha et al. 2010).

\section{Materials and methods}

\section{$2.1 \quad$ Animals}


All animal procedures were approved by the Animal Ethics Committee of the University of Western Australia and conformed to the ARVO Statement for the Use of Animals in Ophthalmic and Vision Research and the policies in the "Guide to the Care and Use of Laboratory Animals" issued by the National Institutes of Health. All efforts were used to minimise pain and suffering during surgery and housed under great care at all times to provide an untroubled and comfortable environment. The pig has been chosen for this study as it has been established as a suitable model having a similar retinal architecture and replicates the features in BRVO as demonstrated in several of our previous clinical and histological studies at different time points from 1 to 11 weeks (McAllister et al. 2009; McAllister et al. 2013; McAllister, Vijayasekaran, and Yu 2013) (Fig. 1).

\subsection{Surgery and tissue processing}

A total of 15 pigs (30 eyes) were used in this study (aged 10 weeks, body weight $\sim 25$ $\mathrm{kg}$ ). Of the 15 pigs, twelve were anaesthetized and sedated with an intramuscular injection using a combination of Zoletil 100 (Tiletamine hypochloride-Zolazepam hypochloride) (4.4 $\mathrm{mg} / \mathrm{Kg}$ ) and Illium Xylazine-100 (Xylazine hydrochloride) $(2.2 \mathrm{mg} / \mathrm{Kg}$ ). They were then intubated, ventilated and maintained on isoflurane in $100 \%$ oxygen. Pupillary dilation was achieved with tropicamide $1 \%$ and phenylephrine hydrochloride $2.5 \%$.

Baseline assessment in all eyes included binocular indirect ophthalmoscopy to exclude pre-existing retinal disorders. After intravenous injection via an ear vein of 10 $\mathrm{mg} / \mathrm{Kg}$ of Rose Bengal dye (Sigma Aldrich, St. Louis, MO, USA), which is a dye with peak absorption of light close to the wavelength of the argon laser. This allows an intravascular thrombus to be created with minimal damage to the vessel wall if appropriate laser powers are used. A photothrombotic BRVO was created in an inferior vein adjacent to the optic disc 
in both eyes of each pig using an argon green laser, $532 \mathrm{~nm}$ wavelength, (Ellex Medical Lasers Ltd., Adelaide, Australia) as described previously (McAllister et al. 2009; McAllister et al. 2013; McAllister, Vijayasekaran, and Yu 2013). This vein was chosen as it creates a small superior field defect and leaves the horizontal and inferior fields unaffected.

Chloramphenicol ointment 1\% (Sigma Pharmaceuticals Ltd, Victoria, Australia) was applied to the eyes after surgery. After surgery the pigs were allowed to recover and were sacrificed at 2, 6, 10 and 20-day post-surgery. The remaining three pigs were used as controls and sacrificed with no intervention. Immediately after sacrifice, the eyes were enucleated, the anterior segment was removed and using an $8 \mathrm{~mm}$ diameter corneal trephine, 2 discs of retina on either side of the occluded vessel outside the focal area of the laser burn and within the area of the BRVO in the retina were cut. One disc was fixed in $4 \%$ paraformaldehyde overnight at $4^{\circ} \mathrm{C}$ and processed in paraffin for TUNEL, basic histology and immunohistochemistry and the other for RT-qPCR from both right and left eyes and from similar areas of the normal eyes without a BRVO. In addition, 2 X $2 \mathrm{~mm}$ pieces adjacent to the discs were cut and fixed in $2.5 \%$ glutaraldehyde in $0.1 \mathrm{M}$ phosphate buffer and processed in epoxy resin for transmission electron microscopy (TEM).

\subsection{TUNEL}

TUNEL technique which is widely employed to measure DNA fragmentation for highlighting apoptotic cells in tissues was used to detect apoptotic degeneration. Briefly $6 \mu \mathrm{m}$ sections were deparaffinised, permeabilised by subjection to heating in a microwave for 4 minutes in sodium citrate buffer $\mathrm{pH} 6.0$ and labelled according to manufacturer's protocol (In situ Fluorescein cell death kit, Roche applied science, Penzberg, Germany). Sections were labelled by incubating with TUNEL reaction mixture consisting of $50 \mu$ l of enzyme solution (terminal deoxynucleotidyl transferase) and $450 \mu 1$ of label solution (nucleotide mixture fluorescein - dUTP) in a humidified chamber at $37^{\circ} \mathrm{C}$ in the dark for 60 minutes. Positive 
and negative controls were also performed by incubating with Dnase I recombinant (1500U/ml in $50 \mathrm{mM}$ Tris $\mathrm{pH} 7.5,10 \mathrm{mM} \mathrm{MgCl} 2,1 \mathrm{mg} / \mathrm{ml} \mathrm{BSA})$ for 10 minutes at room temperature to induce DNA strand breaks and with label solution only respectively prior to labelling. Slides were rinsed in PBS containing a nuclear stain (Hoechst) (Sigma-Aldrich, St. Louis, MO, USA) which stains the DNA of all cells (Crowley, Marfell, and Waterhouse 2016) (prot087221), mounted with antifade medium and viewed under an epifluorescent microscope equipped with fluorescence relevant detection filter (excitation /emission maxima $495 / 519 \mathrm{~nm}$ ) and photographs were taken at a preset setting on the microscope at a magnification of X 60. TUNEL positive cells and all Hoechst stained cells were manually counted.

\subsection{Histology}

Basic histological analysis was performed on haematoxylin and eosin stained $6 \mu \mathrm{m}$ paraffin sections and viewed by light microscopy (LM). In addition, both normal looking and dark shrunken pyknotic nuclei (as TUNEL stains only fragmented nuclei as opposed to hyper condensed pyknotic nuclei) (Crowley, Marfell, and Waterhouse 2016) (prot087221) were manually counted as above. Ultra-structural changes were analysed on $0.1 \mu \mathrm{m}$ ultrathin epoxy resin sections stained with uranyl acetate and lead citrate and viewed by TEM (Philips CM10-2; Philips Electron Optical, Eindhoven, The Netherlands).

\section{$2.5 R T-q P C R$}

RT-qPCR was employed as it is a well-defined method of quantifying gene expression levels. The neural retinas were dissected out from the discs and stored in RNAlater (QIAGEN, Hilden, Germany) at $4^{\circ} \mathrm{C}$ for one week then transferred to $-20^{\circ} \mathrm{C}$. Total RNA was extracted using RNeasy Plus Micro Kit and QIAshredder (QIAGEN). RNA purity was assessed by a NanoDrop ND-2000 spectrophotometer (Thermo Fisher Scientific, Waltham, MA, USA). First- 
strand cDNA was synthesized using $0.5-1 \mu \mathrm{g}$ of total RNA and RT ${ }^{2}$ First Strand Kit (QIAGEN) according to the supplier's protocol. Each qPCR reaction was performed in a $25 \mu 1$ mixture containing $1 \mu \mathrm{l}$ (15-20ng) of cDNA, a pair of porcine-specific primers $(0.4 \mu \mathrm{M})$ and $\mathrm{RT}^{2}$ SYBR-Green qRT-PCR Master Mix (QIAGEN). The primers used in qPCR were GFAP (PPS00012A), AQP4 (PPS01854A), K 4.1 (PPS07806A), VEGF (PPS00495A), SDF-1 (PPSO1281A), IL-6 (PPS00991A), IL8 (PPS00237A) and glyceraldehyde-3-phosphate dehydrogenase (GAPDH, PPS00192A) (RT² qPCR Primer Assay, QIAGEN). In the CFX Connect Real-Time System (Bio-Rad, Hercules, CA, USA), thermocycling conditions were performed as: $95^{\circ} \mathrm{C}$ for 10 minutes, 40 cycles of $95^{\circ} \mathrm{C}$ for 10 seconds and $60^{\circ} \mathrm{C}$ for 20 seconds. The PCR threshold cycle $\left(\mathrm{C}_{\mathrm{T}}\right)$ values were determined by Bio-Rad CFX Manager software version 3.0. All reactions were performed in triplets in two separate runs. In all experiments the relative gene expression levels were normalised against pig house-keeping gene GAPDH. Relative quantitation of gene expression levels in the retinas with BRVO and normal retinas were evaluated using the $-2^{\Delta \Delta \mathrm{C}} \mathrm{T}$ method (Livak and Schmittgen 2001).

\subsection{Immunohistochemistry}

Six- $\mu \mathrm{m}$ thick sections were cut on a microtome (Leica 2040). Deparaffinised sections underwent antigen retrieval (permeabilised) and immunofluorescence staining as described previously (McAllister et al. 2009). Briefly, the sections were treated with blocking serum and then incubated with primary antibody (Table 1). After 2 hours at room temperature or overnight at $4^{\circ} \mathrm{C}$ incubation respectively they were incubated again with the relevant fluorescence Alexa fluor 488 or Alexa fluor 546-conjugated secondary antibody (Invitrogen, Thermo Fisher Scientific, MA, USA) for 1 hour. After each incubation 3 X 3-minute phosphate buffered saline (PBS) washes were performed. Slides were mounted with non-fade mounting medium (Hydromount, National Diagnostics, GA, USA). Negative controls with the omission of the primary antibody and with isotype control was performed. The distribution of 
the labelled protein was visualized under an epifluorescent microscope (Nikon Eclipse E-800: Nikon, Tokyo, Japan) equipped with fluorescence relevant detection filter (excitation / emission maxima $495 / 519 \mathrm{~nm}$ or $556 / 573 \mathrm{~nm}$ ) and photographs were taken at a preset setting on the microscope. Qualitative analysis of immunohistochemistry was performed for the main purpose of determining the tissue regions which showed reactivity.

Table 1. List of primary antibodies used in this study

\begin{tabular}{llc}
\hline Primary antibody & Source & Dilution \\
\hline Polyclonal rabbit anti-cow GFAP & Dako, Glostrup, Denmark & $1: 50$ \\
Polyclonal goat anti-human AQP4 & Santa-Cruz Biotech. Inc. Europe & $1: 100$ \\
Polyclonal rabbit anti-human Kir 4.1 & Alomone lab, Jerusalem, Israel & $1: 200$ \\
Polyclonal rabbit anti-humanVEGFA Santa-Cruz Biotech. Inc. Europe & $1: 50$ \\
Polyclonal rabbit anti-human SDF-1 & Santa-Cruz Biotech. Inc. Europe & $1: 50$ \\
Polyclonal rabbit anti-human IL-6 & Abcam Australia & $1: 100$ \\
Monoclonal mouse anti-human IL-8 & Abcam Australia & $1: 50$ \\
\hline
\end{tabular}

Primary antibodies were validated by western blotting against pig retinal proteins obtained from additional normal pig eyes. Pig retinal tissue was lysed in RIPA lysis buffer (SigmaAldrich, St. Louis, MO, USA) with 1\% protein inhibitor cocktail (Sigma) followed by shaking at $4^{\circ} \mathrm{C}$ for 1 hour. The lysate was then centrifuged at 13,000 rpm for 30 minutes at $4^{\circ} \mathrm{C}$ and the supernatant collected. Protein concentration of the lysate was determined by BioRad Protein Assay (Bio-Rad, Hercules, CA, USA). Twenty micrograms of total protein from tissue lysates was mixed with 1x NuPAGE Novex LDS Sample Buffer (Invitrogen, Thermo Fisher, Scientific, Waltham MA, USA) and heated at $70^{\circ} \mathrm{C}$ for 10 mins before loading onto a NuPAGE 4-12\% Bis-Tris gel (Invitrogen). Protein samples were separated by gel 
electrophoresis in MES SDS Running buffer (Invitrogen) and then transferred onto a PVDF membrane (Immobilon-FL, Merck Millipore, Billerica, MA, USA) at $80 \mathrm{~V}$ for 90 minutes in transfer buffer (25 mM Tris, $190 \mathrm{mM}$ glycine, 20\% methanol, $\mathrm{pH} 8.3$ ). After transfer, the membrane was incubated with blocking buffer $(5 \%$ bovine serum albumin in tris-buffered saline) at room temperature for 1 hour. The membrane then was incubated with anti-IL6 antibody (1:1000), anti-K $\mathrm{K}_{\text {ir }} 4.1$ antibody $(1: 200)$, anti-GFAP antibody (1:1000), anti-VEGF antibody (1:200), anti-IL8 antibody (1:2000), anti-APQ4 antibody (1:200), anti-SDF-1 antibody (1:200), isotype controls, mouse IgG1 (1:500), rabbit IgG (1:40) and Goat IgG (1:40) in blocking buffer with $0.1 \%$ Tween 20 at $4^{\circ} \mathrm{C}$ overnight. After washing in tris-buffered saline with $0.1 \%$ Tween 20 (TBST) 3 times, the membrane was incubated with IRDye $800 \mathrm{CW}$ donkey anti-goat, goat anti-mouse, or goat anti-rabbit IgG (1:10,000; LI-COR) in blocking buffer plus $0.1 \%$ Tween 20 and $0.01 \%$ SDS for 1 hour at room temperature. After three TBST washes, the membrane was washed once with tris-buffered saline without Tween 20 . The membrane was then imaged at $700 \mathrm{~nm}$ and $800 \mathrm{~nm}$ wavelength by the Odyssey Infrared Imager (Model 9120, LI-COR).

\subsection{Statistical analysis}

All data was analysed statistically using SigmaStat 3.5 (Systat Software, San Jose, CA, USA). For cell death and pyknosis a total of 5 eyes were used for each group. Four images from randomly selected slides were examined from each sample (eye) of each group. In each image TUNEL positive cells and all Hoechst stained nuclei were manually counted. Haematoxylin and eosin stained pyknotic and non-pyknotic nuclei were also counted. For cell death and pyknosis, values are expressed as a fraction (percentage) of total number of cells respectively (Crowley et al. 2016) (top070318): Data for multiple comparisons between groups was performed with one-way analysis of variance and Dunn's method. RT-qPCR data was analysed by t-test comparing normal and treated eyes and with one-way analysis of 
variance and Kruskal-Wallis test and Dunn's method for multiple comparison. Probability values $<0.05$ were considered as statistically significant. Data expressed as graphs with mean \pm SEM respectively. A total of 4-6 samples (eyes) were assayed in each group.

\section{Results}

\subsection{Branch retinal vein occlusion}

Immediately after laser treatment of the pig eyes, engorgement of the distal vein and scattered intraretinal haemorrhages were seen, indicating an occlusion had been created. The laser burn was clearly distinguishable on macroscopic examination of the enucleated eye cups in all the eyes in which a vein occlusion was induced. In previous studies, similar photothrombosis in pig retinas have confirmed the presence of an occlusion (Fig.1) (McAllister et al. 2009; McAllister, Vijayasekaran, and Yu 2013).

\subsection{Neurodegeneration}

\subsubsection{TUNEL}

TUNEL staining revealed a large number of dying cells in the ganglion cell layer (GCL) and inner nuclear layer (INL) at 2 days after BRVO with fewer labelled cells observed at all other time points (Fig. 2). Quantification of the percentage of TUNEL positive nuclei showed a significantly higher number in the GCL at 2 days $(\mathrm{p}<0.05)$ compared to all other time points $(6,10$ and 20 days) and the normal retina. There was no significant difference between groups at the other time points after BRVO (normal versus 6,10 and 20; 6 versus 10 and 20; 10 versus 20 days respectively).

In the INL there was a significantly higher number at 2 days compared to 10 days post-BRVO and the normal retina $(\mathrm{p}<0.05)$. There was no significant difference between 2 days and the other two BRVO groups (6 and 20 days) and between groups at the other time 
points after BRVO (normal versus 6, 10 and 20; 6 versus 10 and 20; 10 versus 20 days respectively ( $p>0.05)$ (Fig. 3).

\subsubsection{Pyknotic cells}

Quantification of the percentage of pyknotic cells displaying condensed dark nuclei on haematoxylin eosin sections viewed by LM showed a significantly higher number in the GCL at 2 days compared to 6 days and the normal retina $(\mathrm{p}<0.05)$, however, there was no significant difference at 2 days compared to 10 and 20 days $(p>0.05)$ post occlusion. There was no significant difference between groups at the other time points after BRVO (normal versus 6,10 and 20; 6 versus 10 and 20; 10 versus 20 days respectively) $(\mathrm{p}>0.05)$.

In the INL significantly higher number of pyknotic cells at 2 days compared to normal, and all other time points $(6,10$ and 20 days $)$ after BRVO $(\mathrm{p}<0.05)$ was seen. There was no significant difference between groups at the other time points after BRVO (normal versus 6,10 and 20; 6 versus 10 and 20; 10 versus 20 days respectively) ( $\mathrm{p}>0.05)$ (Fig.4).

\subsubsection{Morphology}

Basic histology of the normal retina showed healthy well organized layers of cells whereas the eyes with BRVO revealed degenerative changes within the cells of the inner retinal layers at all time points. Vacant spaces and pyknotic nuclei were seen in the GCL and the INL (Fig. 5).

TEM of retinal sections at 6,10 and 20 days after BRVO confirmed and extended these findings. The inner limiting membrane (ILM) showed reduced end-feet, degenerating astrocytes and cellular debris. There were degenerating cells in the GCL and in the INL some of the Muller cells appeared pyknotic. Muller fibres showed irregularity and disorganisation with swollen mitochondria. Vacuoles with membranous debris were also 
seen. At 2 days TEM confirmed the presence of apoptosis where there were cells that had undergone alterations in their nuclei and cytosol typical of apoptotic cells in addition to cells with vacuoles that may be undergoing necrosis (Fig. 6).

\subsection{Changes in Gene and Protein Expression}

Changes in gene and protein expression in the post occlusion period were assessed by RT-qPCR (Fig.7) and immunofluorescence (Fig.8-10) analyses. Immunostaining controls, in which the primary antibody was omitted or replaced with an isotype control antibody, demonstrated an absence of specific staining (GFAP, AQP4, $\mathrm{K}_{\mathrm{ir}}$ 4.1, VEGF, SDF-1, IL-6 and -8; Figs. 8 F, L, R, Figs. $9 \mathrm{~F}$ and L, Figs. $10 \mathrm{~F}$ and L respectively). Primary antibodies were validated by western blot analysis (supplementary data).

\subsubsection{GFAP}

RT-qPCR analysis for GFAP mRNA showed significantly higher levels in the BRVO treated eyes at 6,10 and 20 days compared to normal retinas $(\mathrm{p}<0.05)$. Although higher level of GFAP was seen at 2 days it did not reach statistical significance $(p>0.05)$. There was no significant difference among the BRVO treated groups $(2,6,10$ and 20 days post occlusion time points) $(\mathrm{p}>0.05)$.

In the normal retinas intense immune-reactivity of GFAP was seen in the area of the ILM in the astrocytes with hardly any reactivity in the Muller cells. In the retinas with BRVO after 2 days mild reactivity was seen in the astrocytes and in the Muller fibres, at 6 days, reactivity was seen predominantly in the Muller fibres and less in the astrocytes. At 10 days and 20 days strong staining was seen in the ILM and in both Muller cells and astrocytes (Fig. 8 A-E).

\subsubsection{AQP4}


Analysis of AQP4 mRNA by RT-qPCR showed a significantly higher level at 20 days $(p<0.05)$ and no significant difference at 2, 6 and 10 days $(p>0.05)$ in the BRVO treated eyes compared to normal retinas. There was also a significantly higher level at 20 days compared to 2 days in the BRVO treated eyes $(p<0.05)$ with no significance among the other BRVO treated groups (2 versus 6 and 10, 6 versus 10 and 20, 10 versus 20 days post occlusion time points respectively) $(\mathrm{p}>0.05)$.

AQP4 immunoreactivity was detected in the ILM, nerve fibre and, inner and outer plexiform layer and at the perivascular regions of the INL of the normal and BRVO retinas at all time points (Fig. 8 G-K).

\subsubsection{KCNJ10 $\left(K_{\text {ir }} 4.1\right)$}

RT-qPCR mRNA analysis revealed significantly lower levels of KCNJ10 in the BRVO treated retinas at 6 days compared to normal retinas $(\mathrm{p}<0.05)$. Although lower level of $K C N J 10$ was seen at 2 days than normal retinas, it did not reach statistical significance $(p>0.05)$. There was no significant difference among the BRVO treated groups $(2,6,10$ and 20 days post occlusion time points) $(\mathrm{p}>0.05)$.

Kir4.1 immunoreactivity was detected in the ILM, nerve fibre layer, GCL, inner plexiform layer, INL and in the Muller fibres of the normal retinas. Weak staining was seen in the BRVO retinas at all time points. (Fig.8 M-Q).

\subsubsection{VEGF}

RT-qPCR analysis showed a significantly higher level of VEGF at 6 days and significantly lower levels at 2 and 10 days in the treated retinas with BRVO compared to normal retinas $(\mathrm{p}<0.05)$. There was also a significantly higher level at 6 days compared to 10 days in BRVO treated retinas with no significance among the other BRVO treated groups 
( 2 versus 6,10 and 20,6 versus 20, 10 versus 20 days post occlusion time points respectively) $(\mathrm{p}>0.05)$

Immunoreactivity was diffuse and was predominantly in the GCL and INL in normal and BRVO retinas (Fig. 9 A-E).

\subsubsection{CXCL12 (SDF-1)}

RT-qPCR analysis of mRNA CXCL12 showed significantly reduced levels at 2 days and showed a significant increase at 20 days in the BRVO compared to normal retinas $(\mathrm{p}<$ 0.05). There was no significant difference among the BRVO treated groups $(2,6,10$ and 20 days post occlusion time points) $(\mathrm{p}>0.05)$.

Immunoreactivity of SDF-1 was seen in the ILM, GCL, INL and outer plexiform layer. The staining was diffuse through the retinal layers (Fig. 9 G-K).

\subsubsection{IL-6}

RT-qPCR analysis showed significantly reduced levels in IL6 mRNA in the retinas with BRVO at 2 days compared to normal retinas $(\mathrm{p}<0.05)$. Although there was an increase in the levels at 10 and 20 days it did not reach significance. There was no significant difference among the BRVO treated groups $(2,6,10$ and 20 days post occlusion time points) $(\mathrm{p}>0.05)$.

IL-6 immunoreactivity was detected in the ILM, nerve fibre and GCL, diffuse staining in the inner plexiform layer and in the INL of the normal and BRVO retinas at all-time points (Fig. 10 A-E).

\subsubsection{IL-8}

RT-qPCR analysis showed significantly higher levels of IL-8 mRNA in the retinas at 2 and 10 days with BRVO compared to normal retinas $(\mathrm{p}<0.05)$. Although, up regulation was 
seen at 6 days did not reach significance $(p>0.05)$. There was no significant difference among the BRVO treated groups $(2,6,10$ and 20 days post occlusion time points) $(\mathrm{p}>0.05)$.

IL-8 immunoreactivity was seen in the BRVO retinas at all time points. Weak staining was seen in the normal retinas. It was detected in the GCL, INL and diffuse staining in the plexiform layers of all BRVO retinas and in the ILM of retinas at 2, 6 and 10 days respectively (Figure $10 \mathrm{G}-\mathrm{K}$ ).

\section{Discussion}

The success in public and referrer awareness with macular degeneration has led to much earlier presentation of patients with this condition as well as other causes of unilateral visual loss including BRVOs. There is now potential for acute stage treatments including those aimed at preserving retinal neural elements providing the sequence of events following the BRVO is better understood.

The pig model was chosen for this study as its eye is very similar to the human in terms of anatomy, vasculature, similar marker distribution and histogenesis progression (Guduric-Fuchs et al. 2009) as compared to other non-primate mammals and a BRVO can be successfully created as in several studies in the past (McAllister et al. 2009; McAllister, Vijayasekaran, and Yu 2013). Among non-primate models pigs have been suggested as the best model for BRVO. The rodent eye is very small and appropriate focusing of even the smallest available laser beam is extremely difficult (Khayat et al. 2017) The use of Rose Bengal as a photo-enhancing agent allows the creation of an intraluminal thrombus with minimal damage to the vein and overlying retina. Whilst it does not exactly replicate what happens in patients with BRVO as it creates an acute obstruction, it does show the early classical features (Khayat et al. 2017). It is useful as a model to understand the sequence of molecular changes within the retina as the exact timepoint of the obstruction to venous 
outflow is known whilst in humans with BRVO the level of obstruction and associated clinical signs appear to progress over several months before gradually resolving.

To assess neurodegeneration, TUNEL staining to detect dying cells with fragmented DNA (Crowley, Marfell, and Waterhouse 2016) and haematoxylin and eosin staining to identify pyknotic nuclei (hyper condensed DNA) which is an early feature in apoptosis not detected by TUNEL staining, was employed . The TUNEL assay is sensitive, and its methodology has been significantly improved, however, since necrotic cells may also be stained (Zille et al. 2012) by this technique, we also performed TEM to confirm these cells were apoptotic.

Cytokines and proteins play a major role in the preservation or destruction of tissue. $\mathrm{BRB}$ breakdown and MO are associated with the changes in their regulation (Ki et al. 2007). In the present study we investigated these changes in the acute phase and correlated them with histological and apoptotic intraretinal changes. A widely accepted semi quantitative scoring system for immunohistochemistry does not exist as yet and automated systems are not accurate in the interpretation of certain tissues (Fedchenko and Reifenrath 2014) such as the retina. Hence, RT-qPCR was employed to quantitate precisely the change in the gene expression levels of cytokines and proteins whereas immunofluorescence was used for qualitative analysis mainly to detect the cell and tissue locations at which the antigens were immunoreactive.

Muller cells play a vital role in retinal homeostasis. They appear to be amongst the first responders to a variety of injuries to the retina and undergo reactive gliosis (Bringmann et al. 2009). Retinal Muller cell injury is associated directly or indirectly with up or down regulation of cytokines inducing reactive gliosis aimed at mitigating and preventing further damage to the neurons in the retina. However, although the cytokines secreted are initially neuro-protective, overproduction may result in severe gliosis resulting in detrimental effects 
to neuronal and photoreceptor cell viability. Gliosis is characterised by the upregulation of GFAP. GFAP changes in the Muller cells were investigated as it is amongst the earliest and most sensitive manifestation to retinal injury (Rehak et al. 2009). Reactive glial cells can in turn induce cytokine production (Khandelwal, Herman, and Moussa 2011). In our study in the retinas with a BRVO the GFAP mRNA levels were upregulated by 2 days and reached significance at 6,10 and 20 days with peak upregulation seen at 10 days. Staining was localised in both the astrocytes and in the full extent of the Muller cells. This also correlates with the degree of apoptosis seen in the inner retina in the acute stage. LM and TEM also confirmed degenerative changes in astrocytes and Muller cells and their fibres in the BRVO retinas. The pattern of staining of GFAP in the normal retinas was confined to the astrocytes with minimal reactivity seen in the normal healthy Muller cells as has been demonstrated previously (Eisenfeld, Bunt-Milam, and Sarthy 1984).

Muller cells are richly endowed with specialised integral membrane proteins AQP4 and $\mathrm{K}_{\mathrm{ir}} 4.1$ involved in water permeability mediating iso-osmotic fluid exchange (Pannicke et al. 2004). These proteins were also analysed in our study as they are closely associated with retinal oedema. In this study, there was a significant upregulation at 20 days of AQP4 mRNA and no significant difference at the other time points between normal retina and those with BRVO suggesting that water uptake by the Muller cells mediated by AQP4 is not affected in the acute phase of BRVO but may become more significant at later stages with the development of retinal oedema. Similar to these findings AQP4 was largely unaltered in the early stages of a rat model of retinal transient ischemic reperfusion whilst Muller cells within hours significantly down regulate $\mathrm{K}_{\mathrm{ir}} 4.1$ channels, swell and become reactive resulting in ganglion cell death) (Pannicke et al. 2004). $\mathrm{K}_{\mathrm{ir}} 4.1$ levels in our study was similarly significantly down regulated in the BRVO retinas at 6 days compared to the normal retinas, another feature indicative of acute changes in Muller cells. The consequence of such an event 
would lead to an inability to extrude $\mathrm{K}+$, intracellular accumulation of $\mathrm{K}+$, increased intracellular osmotic pressure, an influx of water from the blood into the cells culminating in glial cell swelling and the onset of retinal and MO. Reactive changes such as swelling and death of neurons may not be attributed directly to BRB break down and vascular leakage and may reflect impairment of fluid (metabolic water) clearance (Lobo, Bernardes, and CunhaVaz 2000). It has been suggested that unlike $K_{\text {ir }} 4.1$, the membrane anchoring protein syntrophin of AQP4 is insensitive to ischaemia (Puwarawuttipanit et al. 2006) and this may be the reason why AQP4 was not down regulated in our study. It appears that the most severe neural damage within the retina after an acute BRVO in this model occurs within the first week depicted by the upregulation of GFAP, down regulation of $\mathrm{K}_{\mathrm{ir}} 4.1$ (KCNJ10) expression and the significant loss of GCL and INL cells to apoptosis at 2 days, depicted by TUNEL positive nuclei seen by LM and confirmed by TEM.

The results of this study demonstrated a significant number of TUNEL positive dying cells peaking at 2 days after BRVO in the GCL as seen in previous studies in minipigs with an occlusion (Donati et al. 2008). Apoptosis and inner retinal damage also appears to occur in the early stages of diabetic humans before retinopathy is seen as similar changes were detected in post-mortem eyes (Barber et al. 1998). In the present study, pyknotic cells in the GCL were significantly increased at 2 days post occlusion compared to normal retina. Increased numbers of pyknotic cells were also observed from 6-20 days post occlusion, however these results did not achieve statistical significance (Fig.4), suggesting that pyknosis does not cease instantaneously but could fluctuate at least up to 3 weeks after BRVO. This gives a reasonable window of time for neuroprotective agents to be effectively administered to modulate the associated pathways and rescue the less damaged vulnerable cells which are at an early and potentially reversible phase of apoptosis. The cytoplasmic vacuoles seen at all time points may represent necrotic cell death. Apoptosis and necrosis can occur 
independently, sequentially or simultaneously depending on the intensity of the stimulus (Elmore 2007). This has also been seen in previous studies in the retina and in brain infarction (Donati et al. 2008; Kovacs et al. 1996) prior to recovery in which some of the less damaged cells may be restored. BRVO affects predominantly the inner retina and these adverse changes seen are most likely due to the BRVO rather than laser damage as sampling was performed outside of the focal area of laser damage. Whilst these changes may not replicate the crescendo degree of obstruction occurring in many human subjects with this condition they do imply damage to the inner retina occurs early and this may be a potential area for therapeutic intervention in the future.

Vascular leakage in RVO is associated with hypoxia induced up-regulation of VEGF, together with the increased hydrostatic pressure that occurs due to the obstruction to venous outflow (Kaneda et al. 2011). In previous studies it appears that VEGF in BRVO may be upregulated after the acute event initiated by the activation of VEGF receptors (Martin, Galisteo, and Gutkind 2009). VEGF receptors flt-1 (VEGFR-1) and FLK-1 (VEGFR-2) are present in the GCL and INL cells and in the Muller cell processes respectively (Vinores et al. 2001). In our study, however, there was an initial down regulation of VEGF mRNA expression at 2 days which may be attributed to the loss of a large number of these cells to apoptosis in the GCL and INL resulting in reduced secretion of VEGF at this time point. VEGF expression was noted to be upregulated at 6 days in our study and then decreased at 10 and 20 days. This is similar to other animal acute BRVO and CRVO studies where expression of VEGF upregulation is transient in the acute stage (Rehak et al. 2009) (Rehak et al. 2011). These studies demonstrated VEGF is significantly upregulated at 1 day after a retinal vein occlusion followed by down regulation at 3 and 7 days respectively. Another study (Ebneter et al. 2015) investigating the levels of VEGF in mice by enzyme-linked immunosorbent assay showed similar results being significantly upregulated at 1 day and returning to normal levels 
at 3 days. The rising and falling of VEGF levels may reflect immediate necrotic events as seen in a previous study (Donati et al. 2008).

A direct relationship between IL-6 and VEGF has been previously demonstrated in the aqueous humour of diabetic patients. (Funatsu et al. 2001). This however was not seen in our study where intra retinal changes in gene expression of these cytokines were evaluated rather than intraocular fluid levels. IL-6 expression was significantly downregulated at 2 days although it did show a trend towards higher levels at 10 and 20 days. There are variable reports on the regulation of IL-6 after BRVO. Previous animal studies have shown acute significant upregulation of IL-6 gene expression in the neural retina in CRVO induced rats (Rehak et al. 2011). However, similar to our findings, Lee et al. (Lee et al. 2012) by multiplex array assay reported that aqueous levels of IL-6 in BRVO patients were not significantly different from the control group (without ocular or systemic diseases) while VEGF was upregulated. They suggested that the role of inflammation is less influential in BRVO compared to diabetic retinopathy and in BRVO abrupt blockage may result in sudden upregulation of VEGF.

The results of clinical studies with VEGF inhibitors imply that VEGF is a dominant cytokine in BRVO at least in the later stages in humans. VEGF is present in normal adult eyes in the absence of retinal injury (Kim et al. 1999). Although VEGF is considered a major angiogenic factor that increases microvascular permeability, aqueous levels of VEGF in BRVO patients have been shown to vary. Previous studies have shown VEGF upregulated (Noma et al. 2005) in some and no change or reduced levels in others (Funk et al. 2009; Lim 2011). Most of the information concerning intraocular cytokine changes after RVO stems from human aqueous or vitreous samples in patients with variable and often significant durations of the occlusion (Noma et al. 2005; Funatsu et al. 2012; Noma et al. 2006; Noma et al. 2008; Noma et al. 2010; Noma, Mimura, and Eguchi 2013; Okunuki et al. 2011). These 
studies have shown various degrees of elevated levels of VEGF in both the aqueous and vitreous with the levels dependant on the area of involvement and the degree of retinal ischemia. The role of VEGF in patients as early as 3 weeks after an occlusion has not been studied to the best of our knowledge. Both the BRAVO study and the VIBRANT study investigating the role of anti-VEGF in BRVO enrolled patients 40-60+ days post diagnosis of the BRVO. The actual time the BRVO may have been causing visual symptoms is probably much longer. Our study analysed retinal gene expression levels of these cytokines in the acute early phase that would have been missed by these studies on humans. It appears that VEGF upregulation is delayed, and we have previously shown significant intraretinal VEGF upregulation after BRVO at 11 weeks (McAllister et al. 2009).

In the present study, expression of SDF-1 (CXCL12) was reduced at 2 days post occlusion, which may indicate the loss of secreting cells to apoptosis. The role of SDF-1 in the repair of damaged tissues including the retina has been previously investigated (Brooks et al. 2004). It has been shown to play a major role in proliferative retinopathies and is upregulated in the vitreous in eyes with ocular neovascularisation secondary to diabetic retinopathy and retinal venous occlusive (RVO) disease. In this previous study, elevated vitreous levels of SDF-1 were only found in those eyes with neovascularization, while the levels of SDF-1 were similar to that of control eyes in conditions without intraocular neovascularisation (Ki et al. 2007). In our study at 2, 6 and 10 days SDF-1 was not significantly different to normal retinas but was upregulated at 20 days suggesting this cytokine may have a role in BRVO with disease progression and possibly induced by VEGF or with the onset of intraretinal vascular remodelling (Salvucci et al. 2002). SDF-1 is thought to act in conjunction with VEGF in promoting angiogenesis by recruiting haematopoietic stem cells (Grunewald et al. 2006). 
Kaneda et al. (Kaneda et al. 2011) analysed the cytokine levels in aqueous humour in patients at several months after the onset of BRVO and showed both IL- 6 and -8 were significantly upregulated. IL-8 is an inflammatory chemokine that is upregulated in the acute phase of an ischaemic injury. It is implicated in the recruitment of inflammatory cells including neutrophils and macrophages through CXCR2 (Interleukin 8 receptor $\beta$ ) and stimulates VEGF expression (Martin, Galisteo, and Gutkind 2009; Boisvert et al. 1998; Hristov et al. 2007; Liehn, Schober, and Weber 2004). IL-8 is the most significantly associated cytokine implicated with tissue damage parameters in BRVO (Kaneda et al. 2011). IL-8 is neurotoxic (Thirumangalakudi et al. 2007) and its overproduction could lead to cell death. It precedes and controls the expression of VEGF in endothelial cells. In our study IL-8 mRNA expression was significantly upregulated at 2 and 10 days after BRVO and also remained elevated over the duration of the study to 20 days. In our study VEGF expression was only seen to be significantly upregulated at 6 days although we have previously shown it to be upregulated later and as IL-8 precedes VEGF upregulation, this would be consistent. It has been suggested that IL-8 is the main inflammatory factor involved in MO associated with BRVO (Noma et al. 2014) and has been correlated with central macular thickness and also with the severity of retinal ischaemia.

Evidence from experimental studies of intraretinal cytokine levels at known time points in retinal models similar to that of humans is lacking. Experimental studies with young animals may not replicate exactly the changes seen in elderly arteriosclerotic humans and acute studies such as this do not replicate the rate of intra retinal changes. Pigs, especially young ones may have more aggressive healing and vascular remodelling responses compared to that of humans. Alshareef et al. (Alshareef et al. 2016) demonstrated a significant reduction in ganglion cell-inner plexiform layer thickness regardless of the duration of BRVO (two groups of less and more than 3 months respectively) indicating generalised neuronal 
degeneration in eyes with BRVO remains a significant but yet unaddressed issue and models such as this are useful to explore possible mechanisms.

This study differs from several other studies in that the levels of cytokine expression in the retina were analysed as opposed to that in the aqueous or vitreous which may not reflect the actual intraretinal levels. Cytokines are likely to be more concentrated in the area of the lesion and there may be different rates at which they diffuse across the ILM in addition to any binding to extracellular matrix along its path. Furthermore, most of these studies have been performed on patients with chronic BRVOs with different durations and extent of involvement. Consequently, the levels of the cytokine milieu may differ one from another depending on the time of onset of the disease and its severity. Therefore, to establish the choice of the appropriate treatment, at the appropriate times based on these previous findings would be challenging. Current treatment options for BRVO include laser photocoagulation, intravitreal steroids and intravitreal VEGF antibodies. The effectiveness of macular grid laser is minimal, steroids are effective in the short term and whilst VEGF antibodies have proven to be more successful this does require frequent injections for extensive periods (Heier et al. 2012). VEGF is however a physiological factor that is essential for the preservation of neurons (Nishijima et al. 2007). In the acute phase of BRVO when it appears that the likelihood of neuronal damage is highest, the possibility exists, at least in this acute experimental model, that anti-VEGF therapy may potentially exacerbate this. In patients with RVO receiving VEGF inhibitors, OCT studies have shown thinning of the nerve fibre layer and inner retina, despite resolution of the MO (Klein et al. 2008; Lima et al. 2011; Alshareef et al. 2016) . The pathogenesis of this neural damage is probably multifactorial with hypoxia and induced cytokine dysregulation all potentially involved which is not addressed by current treatments. Any potential role that VEGF antagonists may have in this remains at this stage theoretic. Whilst these advances in treatment for BRVO represent a major advance, 
restoration of vision is often incomplete despite the MO eventually resolving (Heier et al. 2012).

Evidence from experimental studies of intraretinal cytokine levels in RVOs at known time points in retinal models similar to that of humans is lacking and to the best of our knowledge this has not been previously investigated in the pig model. Previous studies on RVOs have been performed on rodents (Rehak et al. 2011; Rehak et al. 2009; Ebneter et al. 2015) and SDF-1 and IL-8 have not been investigated in these studies. There was some variation in our present study in the early phase compared to these previous studies and these may be attributed to, firstly, a difference in the animal species (pigs vs rodents) as a range of histological and functional differences exist between individual species and several antibodies which labelled the same cell types in pig and human retina have shown different specificity in the mouse (Guduric-Fuchs et al. 2009). Secondly, there was a difference in the method of thrombus induction used in the rat model (Rehak et al. 2011) where sodium fluorescein instead of Rose Bengal was used and thirdly, the severity and extent of the blockage may differ particularly as a result of the extreme difference in rodents such as in the size of the eye being much smaller and the large intraocular lens in relation to the laser beam, all of which may reflect varied outcomes in the intraretinal changes.

This present study indicates that the responses in the acute phase of BRVO include inflammation as seen by the upregulation of inflammatory cytokines and breakdown of osmohomeostasis by the dislocation of Ki 4.1 water channel. Apoptosis and inner retinal damage appear to occur in the early acute stages as demonstrated in this study. This study does have some limitations as the effects of the laser used to induce the BRVO may in itself had some possible effect on intraretinal cytokine levels outside of the area of direct injury. In conclusion whilst this acute model of BRVO does not exactly replicate the changes that occur in a human with this condition it is of value in understanding the neuronal and 
intraretinal cytokine changes occurring in the early stages of this condition as the time from the initiation of the occlusive event is known. This photothrombotic model produces an occlusion that is acute and relatively more severe than the slow and progressive occlusion and retinal changes seen in most patients with a BRVO (Hayreh et al. 2001). It does demonstrate that neuronal degeneration and alteration in homeostasis occurs early in this condition and that there is a potential for additional treatments in this early phase that may be able to reverse apoptosis in those cells that are less severely affected. Neuroprotective treatments and targeting of dislocated water channels may be advantageous in attenuating the progression of BRVO induced neural damage.

VEGF is not upregulated immediately in this model and the theoretic possibility exists that early treatment with antagonists to this cytokine which does in itself have neuroprotective capabilities before it is fully upregulated may be counterproductive. As the pathogenesis of BRVO clinically differs significantly from this experimental model this would not affect current management, however further investigation into potentially effective neuroprotective agents is required.

Acknowledgments

The authors thank Slavica Pervan for tissue sectioning and Shang-Chih Chen for western blot analysis for validation of antibodies. 
References

Abu-El-Asrar, A. M., L. Dralands, L. Missotten, I. A. Al-Jadaan, and K. Geboes. 2004. 'Expression of apoptosis markers in the retinas of human subjects with diabetes', Invest Ophthalmol Vis Sci, 45: 2760-6.

Alshareef, R. A., G. Barteselli, Q. You, A. Goud, A. Jabeen, H. L. Rao, A. Jabeen, and J. Chhablani. 2016. 'In vivo evaluation of retinal ganglion cells degeneration in eyes with branch retinal vein occlusion', Br J Ophthalmol, 100: 1506-10.

Baglivo, E., A. Dosso, and C. Pournaras. 1997. 'Thrombus and branch retinal vein occlusion', Graefes Arch Clin Exp Ophthalmol, 235: 10-3.

Barber, A. J., E. Lieth, S. A. Khin, D. A. Antonetti, A. G. Buchanan, and T. W. Gardner. 1998. 'Neural apoptosis in the retina during experimental and human diabetes. Early onset and effect of insulin', J Clin Invest, 102: 783-91.

Boisvert, W. A., R. Santiago, L. K. Curtiss, and R. A. Terkeltaub. 1998. 'A leukocyte homologue of the IL- 8 receptor CXCR-2 mediates the accumulation of macrophages in atherosclerotic lesions of LDL receptor-deficient mice', J Clin Invest, 101: 353-63.

Bringmann, A., I. Iandiev, T. Pannicke, A. Wurm, M. Hollborn, P. Wiedemann, N. N. Osborne, and A. Reichenbach. 2009. 'Cellular signaling and factors involved in Muller cell gliosis: neuroprotective and detrimental effects', Prog Retin Eye Res, 28: 423-51.

Bringmann, A., T. Pannicke, J. Grosche, M. Francke, P. Wiedemann, S.N. Skatchkov, N.N. Osborne, and A. Reichenbach. 2006. 'Muller cells in the healthy and diseased retina', Prog. Retin. Eye Res, 25: 397-424.

Brooks, H.L., Jr., Caballero S Jr, C.K. Newell, R.L. Steinmetz, D. Watson, M.S. Segal, J.K. Harrison, E.W. Scott, and M.B. Grant. 2004. 'Vitreous levels of vascular endothelial growth factor and stromal-derived factor 1 in patients with diabetic retinopathy and cystoid macular edema before and after intraocular injection of triamcinolone', Arch. Ophthalmol, 122: 1801-07.

Campochiaro, P. A., W. L. Clark, D. S. Boyer, J. S. Heier, D. M. Brown, R. Vitti, H. Kazmi, A. J. Berliner, K. Erickson, K. W. Chu, Y. Soo, Y. Cheng, and J. A. Haller. 2015. 'Intravitreal aflibercept for macular edema following branch retinal vein occlusion: the 24-week results of the VIBRANT study', Ophthalmology, 122: 538-44.

Campochiaro, P.A., J.S. Heier, L. Feiner, S. Gray, N. Saroj, A.C. Rundle, W.Y. Murahashi, and R.G. Rubio. 2010. 'Ranibizumab for macular edema following branch retinal vein occlusion: six-month primary end point results of a phase III study', Ophthalmology, 117: 1102-12.

Crowley, L. C., B. J. Marfell, A. P. Scott, J. A. Boughaba, G. Chojnowski, M. E. Christensen, and N. J. Waterhouse. 2016. 'Dead Cert: Measuring Cell Death', Cold Spring Harb Protoc, 2016: pdb top070318.

Crowley, L. C., B. J. Marfell, and N. J. Waterhouse. 2016. 'Detection of DNA Fragmentation in Apoptotic Cells by TUNEL', Cold Spring Harb Protoc, 2016: pdb prot087221.

Diez-Roux, G., and R. A. Lang. 1997. 'Macrophages induce apoptosis in normal cells in vivo', Development, 124: 3633-8.

Donati, G., A. Kapetanios, M. Dubois-Dauphin, and C. J. Pournaras. 2008. 'Caspase-related apoptosis in chronic ischaemic microangiopathy following experimental vein occlusion in mini-pigs', Acta Ophthalmol, 86: 302-6.

Ebneter, A., C. Agca, C. Dysli, and M. S. Zinkernagel. 2015. 'Investigation of retinal morphology alterations using spectral domain optical coherence tomography in a mouse model of retinal branch and central retinal vein occlusion', PLoS One, 10: e0119046. 
Eisenfeld, A.J., A.H. Bunt-Milam, and P.V. Sarthy. 1984. 'Muller cell expression of glial fibrillary acidic protein after genetic and experimental photoreceptor degeneration in the rat retina', Invest Ophthalmol. Vis. Sci, 25: 1321-28.

Elmore, S. 2007. 'Apoptosis: a review of programmed cell death', Toxicol Pathol, 35: 495516.

Fedchenko, N., and J. Reifenrath. 2014. 'Different approaches for interpretation and reporting of immunohistochemistry analysis results in the bone tissue - a review', Diagn Pathol, 9: 221.

Frangieh, G. T., W. R. Green, E. Barraquer-Somers, and D. Finkelstein. 1982. 'Histopathologic study of nine branch retinal vein occlusions', Arch Ophthalmol, 100: 1132-40.

Funatsu, H., H. Noma, T. Mimura, and S. Eguchi. 2012. 'Vitreous inflammatory factors and macular oedema', Br J Ophthalmol, 96: 302-4.

Funatsu, H., H. Yamashita, E. Shimizu, R. Kojima, and S. Hori. 2001. 'Relationship between vascular endothelial growth factor and interleukin-6 in diabetic retinopathy', Retina, 21: 469-77.

Funk, M., K. Kriechbaum, F. Prager, T. Benesch, M. Georgopoulos, G. J. Zlabinger, and U. Schmidt-Erfurth. 2009. 'Intraocular concentrations of growth factors and cytokines in retinal vein occlusion and the effect of therapy with bevacizumab', Invest Ophthalmol Vis Sci, 50: 1025-32.

Grunewald, M., I. Avraham, Y. Dor, E. Bachar-Lustig, A. Itin, S. Jung, S. Chimenti, L. Landsman, R. Abramovitch, and E. Keshet. 2006. 'VEGF-induced adult neovascularization: recruitment, retention, and role of accessory cells', Cell, 124: 17589.

Guduric-Fuchs, J., L. J. Ringland, P. Gu, M. Dellett, D. B. Archer, and T. Cogliati. 2009. 'Immunohistochemical study of pig retinal development', Mol Vis, 15: 1915-28.

Hayreh, S.S., B. Zimmerman, M.J. McCarthy, and P. Podhajsky. 2001. 'Systemic diseases associated with various types of retinal vein occlusion', Am. J. Ophthalmol, 131: 6177.

Heier, J. S., P. A. Campochiaro, L. Yau, Z. Li, N. Saroj, R. G. Rubio, and P. Lai. 2012. 'Ranibizumab for macular edema due to retinal vein occlusions: long-term follow-up in the HORIZON trial', Ophthalmology, 119: 802-9.

Hristov, M., A. Zernecke, K. Bidzhekov, E. A. Liehn, E. Shagdarsuren, A. Ludwig, and C. Weber. 2007. 'Importance of CXC chemokine receptor 2 in the homing of human peripheral blood endothelial progenitor cells to sites of arterial injury', Circ Res, 100: 590-7.

Huang, H., J. K. Gandhi, X. Zhong, Y. Wei, J. Gong, E. J. Duh, and S. A. Vinores. 2011. 'TNFalpha is required for late BRB breakdown in diabetic retinopathy, and its inhibition prevents leukostasis and protects vessels and neurons from apoptosis', Invest Ophthalmol Vis Sci, 52: 1336-44.

Joo, C. K., J. S. Choi, H. W. Ko, K. Y. Park, S. Sohn, M. H. Chun, Y. J. Oh, and B. J. Gwag. 1999. 'Necrosis and apoptosis after retinal ischemia: involvement of NMDA-mediated excitotoxicity and p53', Invest Ophthalmol Vis Sci, 40: 713-20.

Kaneda, S., D. Miyazaki, S. Sasaki, K. Yakura, Y. Terasaka, K. Miyake, Y. Ikeda, T. Funakoshi, T. Baba, A. Yamasaki, and Y. Inoue. 2011. 'Multivariate analyses of inflammatory cytokines in eyes with branch retinal vein occlusion: relationships to bevacizumab treatment', Invest Ophthalmol. Vis. Sci, 52: 2982-88.

Kerr, J. F., A. H. Wyllie, and A. R. Currie. 1972. 'Apoptosis: a basic biological phenomenon with wide-ranging implications in tissue kinetics', Br J Cancer, 26: 239-57. 
Khandelwal, P. J., A. M. Herman, and C. E. Moussa. 2011. 'Inflammation in the early stages of neurodegenerative pathology', J Neuroimmunol, 238: 1-11.

Khayat, M., N. Lois, M. Williams, and A. W. Stitt. 2017. 'Animal Models of Retinal Vein Occlusion', Invest Ophthalmol Vis Sci, 58: 6175-92.

Ki, I., N. Arimura, Y. Noda, K. Yamakiri, N. Doi, T. Hashiguchi, I. Maruyama, M. Shimura, and T. Sakamoto. 2007. 'Stromal-derived factor-1 and inflammatory cytokines in retinal vein occlusion', Curr. Eye Res, 32: 1065-72.

Kim, C. S., K. S. Shin, H. J. Lee, Y. J. Jo, and J. Y. Kim. 2014. 'Sectoral retinal nerve fiber layer thinning in branch retinal vein occlusion', Retina, 34: 525-30.

Kim, I., A. M. Ryan, R. Rohan, S. Amano, S. Agular, J. W. Miller, and A. P. Adamis. 1999. 'Constitutive expression of VEGF, VEGFR-1, and VEGFR-2 in normal eyes', Invest Ophthalmol Vis Sci, 40: 2115-21.

Klein, R., B.E. Klein, S.E. Moss, and S.M. Meuer. 2000. 'The epidemiology of retinal vein occlusion: the Beaver Dam Eye Study', Trans. Am. Ophthalmol. Soc, 98: 133-41.

Klein, R., S.E. Moss, S.M. Meuer, and B.E. Klein. 2008. 'The 15-year cumulative incidence of retinal vein occlusion: the Beaver Dam Eye Study', Arch. Ophthalmol, 126: 51318.

Kovacs, Z., K. Ikezaki, K. Samoto, T. Inamura, and M. Fukui. 1996. 'VEGF and flt. Expression time kinetics in rat brain infarct', Stroke, 27: 1865-72; discussion 72-3.

Kumar, B., D. Y. Yu, W. H. Morgan, C. J. Barry, I. J. Constable, and I. L. McAllister. 1998. 'The distribution of angioarchitectural changes within the vicinity of the arteriovenous crossing in branch retinal vein occlusion', Ophthalmology, 105: 424-7.

Labat-gest, V., and S. Tomasi. 2013. 'Photothrombotic ischemia: a minimally invasive and reproducible photochemical cortical lesion model for mouse stroke studies', $J$ Vis Exp.

Lee, W. J., M. H. Kang, M. Seong, and H. Y. Cho. 2012. 'Comparison of aqueous concentrations of angiogenic and inflammatory cytokines in diabetic macular oedema and macular oedema due to branch retinal vein occlusion', Br J Ophthalmol, 96: 142630.

Liehn, E. A., A. Schober, and C. Weber. 2004. 'Blockade of keratinocyte-derived chemokine inhibits endothelial recovery and enhances plaque formation after arterial injury in ApoE-deficient mice', Arterioscler Thromb Vasc Biol, 24: 1891-6.

Lim, J. W. 2011. 'Intravitreal bevacizumab and cytokine levels in major and macular branch retinal vein occlusion', Ophthalmologica, 225: 150-4.

Lima, V. C., L. Yeung, L. C. Castro, G. Landa, and R. B. Rosen. 2011. 'Correlation between spectral domain optical coherence tomography findings and visual outcomes in central retinal vein occlusion', Clin Ophthalmol, 5: 299-305.

Livak, K. J., and T. D. Schmittgen. 2001. 'Analysis of relative gene expression data using real-time quantitative PCR and the 2(-Delta Delta C(T)) Method', Methods, 25: 402-8.

Lobo, C.L., R.C. Bernardes, and J.G. Cunha-Vaz. 2000. 'Alterations of the blood-retinal barrier and retinal thickness in preclinical retinopathy in subjects with type 2 diabetes', Arch. Ophthalmol, 118: 1364-69.

Martin, D., R. Galisteo, and J. S. Gutkind. 2009. 'CXCL8/IL8 stimulates vascular endothelial growth factor (VEGF) expression and the autocrine activation of VEGFR2 in endothelial cells by activating NFkappaB through the CBM (Carma3/Bc110/Malt1) complex', J Biol Chem, 284: 6038-42.

McAllister, I. L., S. Vijayasekaran, S. D. Chen, and D. Y. Yu. 2009. 'Effect of triamcinolone acetonide on vascular endothelial growth factor and occludin levels in branch retinal vein occlusion', Am J Ophthalmol, 147: 838-46, 46 e1-2.

McAllister, I. L., S. Vijayasekaran, W. Xia, and D. Y. Yu. 2013. 'Evaluation of the ability of a photocoagulator to rupture the retinal vein and Bruch's membrane for potential vein 
bypass in retinal vein occlusion', Ophthalmic Surg Lasers Imaging Retina, 44: 26873.

McAllister, I. L., S. Vijayasekaran, and D. Y. Yu. 2013. 'Intravitreal tenecteplase (metalyse) for acute management of retinal vein occlusions', Invest Ophthalmol Vis Sci, 54: 4910-8.

Mitchell, P., W. Smith, and A. Chang. 1996. 'Prevalence and associations of retinal vein occlusion in Australia. The Blue Mountains Eye Study', Arch. Ophthalmol, 114: 1243-47.

Nishijima, K., Y. S. Ng, L. Zhong, J. Bradley, W. Schubert, N. Jo, J. Akita, S. J. Samuelsson, G. S. Robinson, A. P. Adamis, and D. T. Shima. 2007. 'Vascular endothelial growth factor-A is a survival factor for retinal neurons and a critical neuroprotectant during the adaptive response to ischemic injury', Am J pathol, 171: 53-67.

Noma, H., H. Funatsu, T. Mimura, and K. Shimada. 2010. 'Increase of aqueous inflammatory factors in macular edema with branch retinal vein occlusion: a case control study', $J$ Inflamm (Lond), 7: 44.

Noma, H., H. Funatsu, M. Yamasaki, H. Tsukamoto, T. Mimura, T. Sone, T. Hirayama, H. Tamura, H. Yamashita, A. Minamoto, and H. K. Mishima. 2008. 'Aqueous humour levels of cytokines are correlated to vitreous levels and severity of macular oedema in branch retinal vein occlusion', Eye (Lond), 22: 42-8.

Noma, H., H. Funatsu, M. Yamasaki, H. Tsukamoto, T. Mimura, T. Sone, K. Jian, I. Sakamoto, K. Nakano, H. Yamashita, A. Minamoto, and H. K. Mishima. 2005. 'Pathogenesis of macular edema with branch retinal vein occlusion and intraocular levels of vascular endothelial growth factor and interleukin-6', Am J Ophthalmol, 140: 256-61.

Noma, H., T. Mimura, and S. Eguchi. 2013. 'Association of inflammatory factors with macular edema in branch retinal vein occlusion', JAMA Ophthalmol, 131: 160-5.

Noma, H., T. Mimura, K. Yasuda, and M. Shimura. 2014. 'Role of soluble vascular endothelial growth factor receptors-1 and -2, their ligands, and other factors in branch retinal vein occlusion with macular edema', Invest Ophthalmol Vis Sci, 55: 3878-85.

Noma, H., A. Minamoto, H. Funatsu, H. Tsukamoto, K. Nakano, H. Yamashita, and H.K. Mishima. 2006. 'Intravitreal levels of vascular endothelial growth factor and interleukin-6 are correlated with macular edema in branch retinal vein occlusion', Graefes Arch. Clin. Exp. Ophthalmol, 244: 309-15.

Okunuki, Y., Y. Usui, N. Katai, T. Kezuka, M. Takeuchi, H. Goto, and Y. Wakabayashi. 2011. 'Relation of intraocular concentrations of inflammatory factors and improvement of macular edema after vitrectomy in branch retinal vein occlusion', $\mathrm{Am}$ J Ophthalmol, 151: 610-16 e1.

Pannicke, T., I. Iandiev, O. Uckermann, B. Biedermann, F. Kutzera, P. Wiedemann, H. Wolburg, A. Reichenbach, and A. Bringmann. 2004. 'A potassium channel-linked mechanism of glial cell swelling in the postischemic retina', Mol. Cell Neurosci, 26: 493-502.

Puwarawuttipanit, W., A. D. Bragg, D. S. Frydenlund, M. N. Mylonakou, E. A. Nagelhus, M. F. Peters, N. Kotchabhakdi, M. E. Adams, S. C. Froehner, F. M. Haug, O. P. Ottersen, and M. Amiry-Moghaddam. 2006. 'Differential effect of alpha-syntrophin knockout on aquaporin-4 and Kir4.1 expression in retinal macroglial cells in mice', Neuroscience, 137: 165-75.

Rehak, M., F. Drechsler, P. Koferl, M. Hollborn, P. Wiedemann, A. Bringmann, and L. Kohen. 2011. 'Effects of intravitreal triamcinolone acetonide on retinal gene expression in a rat model of central retinal vein occlusion', Graefes Arch Clin Exp Ophthalmol, 249: 1175-83. 
Rehak, M., M. Hollborn, I. Iandiev, T. Pannicke, A. Karl, A. Wurm, L. Kohen, A. Reichenbach, P. Wiedemann, and A. Bringmann. 2009. 'Retinal gene expression and Muller cell responses after branch retinal vein occlusion in the rat', Invest Ophthalmol. Vis. Sci, 50: 2359-67.

Rogers, S. L., R. L. McIntosh, L. Lim, P. Mitchell, N. Cheung, J. W. Kowalski, H. P. Nguyen, J. J. Wang, and T. Y. Wong. 2010. 'Natural history of branch retinal vein occlusion: an evidence-based systematic review', Ophthalmology, 117: 1094-101 e5.

Rogers, S., R.L. McIntosh, N. Cheung, L. Lim, J.J. Wang, P. Mitchell, J.W. Kowalski, H. Nguyen, and T.Y. Wong. 2010. 'The prevalence of retinal vein occlusion: pooled data from population studies from the United States, Europe, Asia, and Australia', Ophthalmology, 117: 313-19.

Salvucci, O., L. Yao, S. Villalba, A. Sajewicz, S. Pittaluga, and G. Tosato. 2002. 'Regulation of endothelial cell branching morphogenesis by endogenous chemokine stromalderived factor-1', Blood, 99: 2703-11.

Sapieha, P., D. Hamel, Z. Shao, J. C. Rivera, K. Zaniolo, J. S. Joyal, and S. Chemtob. 2010. 'Proliferative retinopathies: angiogenesis that blinds', Int J Biochem Cell Biol, 42: 512.

Silva, R. M., J. R. Faria de Abreu, and J. G. Cunha-Vaz. 1995. 'Blood-retina barrier in acute retinal branch vein occlusion', Graefes Arch Clin Exp Ophthalmol, 233: 721-6.

The Branch Vein Occlusion Study Group. 1984. 'Argon laser photocoagulation for macular edema in branch vein occlusion', Am J Ophthalmol, 98: 271-82.

Thirumangalakudi, L., L. Yin, H. V. Rao, and P. Grammas. 2007. 'IL-8 induces expression of matrix metalloproteinases, cell cycle and pro-apoptotic proteins, and cell death in cultured neurons', J Alzheimers Dis, 11: 305-11.

Vinores, S. A., N. L. Derevjanik, A. Shi, M. A. Vinores, D. A. Klein, and J. A. WhittumHudson. 2001. 'Vascular endothelial growth factor (VEGF), transforming growth factor-beta (TGFbeta), and interleukin-6 (IL-6) in experimental herpesvirus retinopathy: association with inflammation and viral infection', Histol Histopathol, 16: 1061-71.

Wong, T. Y., and I. U. Scott. 2010. 'Clinical practice. Retinal-vein occlusion', N Engl J Med, 363: 2135-44.

Zille, M., T. D. Farr, I. Przesdzing, J. Muller, C. Sommer, U. Dirnagl, and A. Wunder. 2012. 'Visualizing cell death in experimental focal cerebral ischemia: promises, problems, and perspectives', J Cereb Blood Flow Metab, 32: 213-31. 


\section{Legends}

\section{Figure 1: Photothrombotic branch retinal vein Occlusion.}

A: Macroscopic view of the eyecup of a BRVO retina at 1 weeks showing attenuation of flow of blood (dotted circle) towards the optic disc (OD) at the laser burn site.

B: Light micrograph of retina at 1 week in which BRVO was attempted showing the lumen of the vein occupied almost completely by a thrombus packed with red blood cells clumped together. A macrophage is seen close to the occluded vein (red arrow). Scale bar $=30 \mu \mathrm{m}$.

C: Transmission electron micrograph of a BRVO showing an area of the thrombus composed of packed stagnant red blood cells adjacent to the wall of a retinal vein with endothelial cell. Scale bar $=0.3 \mu \mathrm{m}$.

\section{Figure 2: TUNEL labelling.}

TUNEL staining of normal retina (A) showing an absence of TUNEL positive cells. Blood cells show yellow autofluoresecence, (C) at 2 days several cells in the ganglion cell layer (GCL) and the inner nuclear (INL) show staining of apoptotic cells (arrow) and (E) scarce staining at 6 days after a BRVO was created. Positive control $(G)$ incubated with Dnase I to damage nuclei showed intense staining (arrow) and negative control (H) incubated with label solution only showed an absence of staining. Hoechst treated retina (B, D and F) showing bright nuclear staining of all cells of normal retina, at 2 and 6 days post occlusion respectively. ILM: Inner limiting membrane. Scale bar $=17 \mu \mathrm{m}$.

Figure 3. Graph showing percentage of dying TUNEL positive cells.

Graph demonstrating percentage of TUNEL positive cell counts significantly higher $(*)$ at 2 days in the ganglion cell layer (GCL) compared to the normal retina and at 6,10 and 20 
days, and in the inner nuclear layer (INL) compared to normal retina and at 10 days respectively after a BRVO was attempted.

\section{Figure 4. Graph showing percentage of pyknotic nuclei.}

Graph demonstrating pyknotic celll counts significantly higher at 2 days $(*)$ in the ganglion cell layer (GCL) compared to normal retina and retina at 6 days and in the inner nuclear layer (INL) at 2 days compared to normal retina and retina at 6,10 and 20 respectively after a BRVO was attempted.

\section{Figure 5: Histology - Light Microscopy.}

Light micrographs of normal retina $\mathbf{A}$, showing healthy retinal structure with ganglion cells with nuclei and nucleolus in the ganglion cell layer (GCL), normal looking inner nuclear (INL) and outer nuclear layer (ONL). B, retina 2 days after BRVO was attempted retina showing vacuoles $\left(^{*}\right)$ in the GCL and INL, C, 6 days after BRVO was attempted displaying vacuoles (*) in the GCL and INL, pyknosis in the INL and both INL and ONL showing displacement of their nuclei. D, retina 10 days after BRVO was attempted displaying more severe damage with vacuoles $(*)$ in the GCL and INL in which pyknotic cells are seen with reduced layers of nuclei. E, retina 20 days after BRVO was attempted displaying vacuoles (*) in the GCL and INL in which pyknotic cells are seen. ONL shows mild displacement of nuclei. Scale bar $=11 \mu \mathrm{m}$.

Figure 6: Histology - Transmission Electron Microscopy. 
Transmission electron micrographs of a retina 2 days after BRVO was attempted showing $\mathbf{A}$, a cell in the ganglion cell layer with apoptotic changes in the nuclei $(\mathrm{N})$ including chromatin in the nuclear periphery, organelles still intact but with condensation of the cystosol, $\mathbf{B}$, cells in the inner nuclear layer showing changes in the nuclei $(\mathrm{N})$, vacuoles $\left({ }^{*}\right)$ and myelin debris, scale bar $=0.8 \mu \mathrm{m}: \quad \mathbf{C}, 20$ days after BRVO was attempted showing inner limiting membrane composed of reduced Muller end-feet (E) membranous debris and an astrocyte with nucleous $(\mathrm{N})$ in the process of degeneration showing vacuolation $(*)$ and debris of its soma. Vacuoles are also seen among Muller cell fibres (MF) containing swollen mitochondria $(\mathrm{M})$, scale bar $=5 \mu \mathrm{m}$ : D, Muller cell fibres interior appear disorganised and appear to have lost the regular tubular structure. Vacuoles and mitochondrial swelling is also seen, scale bar $=3 \mu \mathrm{m}$ : E, Degenerating Muller cells (MC) with extending fibres containing swollen mitochondria and a loss of cell organelles are seen: F, Inner nuclear layer showing a bipolar cell (BP), adjoining vacant spaces $\left(^{*}\right)$ that may have been occupied by cells and a Muller cell undergoing degenerative changes depicted by vacuoles in its soma. Scale bar $=5$ $\mu \mathrm{m}$.

\section{Figure 7: RT-qPCR}

Graph of RT-qPCR demonstrating the relative expression levels of the pig retinal genes (normalised against the housekeeping gene glyceraldehyde-3-phosphate dehydrogenase) for intermediate filament glial fibrillary acidic protein (GFAP), channel proteins, aquaporin 4 (AQP4), inward rectifier potassium channel $10\left(\mathrm{~K}_{\mathrm{ir}} 4.1\right)$ and inflammatory cytokines vascular endothelial growth factor (VEGF), stromal derived growth factor-1 $\alpha$ (SDF-1), interleukin 6 (IL-6), interleukin 8 (IL-8) in BRVO and normal retinas. * indicates statistical significance (p $<0.05)$ compared to controls.

Figure 8: Immunohistochemistry of GFAP, AQP4 and Kir 4.1. 
Immunolocalisation (arrow) of GFAP (A, normal; B, 2 days; C, 6 days; D, 10 days; E, 20 days; F, negative control), AQP4 (G, normal; H, 2 days; I, 6 days; J, 10 days; K, 20 days; $\mathbf{L}$, negative control) and $\mathrm{K}_{\mathrm{ir}}$ 4.1. (M, normal; $\mathbf{N}, 2$ days; $\mathbf{O}, 6$ days; $\mathbf{P}, 10$ days; $\mathbf{Q}, 20$ days; $\mathbf{R}$, negative control) in the retinas of normal and eyes enucleated at 2, 6, 10 and 20 days after a BRVO was created.

GFAP is seen localised in the astrocytes in retina of normal (A) and BRVO retinas at $10(\mathbf{C})$ and 20 (D) days respectively, Muller cells show staining in the retinas with BRVO at all time points.

AQP4 staining is seen predominantly in the inner limiting membrane and in the perivascular regions in the normal and BRVO retinas at all time points.

$\mathrm{K}_{\mathrm{ir}} 4.1$ showing intense staining in all the layers and in the Muller fibres of the normal retina and weak staining in the BRVO retinas at all other time points.

Autofluorescence $\left(^{*}\right)$ of inner segments and blood cells is seen in most of the retinas including the negative control.

ILM, Inner limiting membrane; ONL, outer nuclear layer: Scale bar $=30 \mu \mathrm{m}$.

Figure 9: Immunohistochemistry of VEGF and SDF-1.

Immunolocalisation (arrow) of VEGF (A, normal; B, 2 days; C, 6 days; D 10 days; E, 20 days; F, negative control) ,SDF -1 (G, normal; H, 2 days; I, 6 days; J, 10 days; $\mathbf{K}, 20$ days; $\mathbf{L}$, negative control) in the retinas of normal and eyes enucleated at 2, 6,10 and 20 days after a BRVO was created.

VEGF and: SDF-1 showing diffuse staining predominantly in the inner retinal layers of normal and treated retinas.

ILM, Inner limiting membrane; ONL, outer nuclear layer. Scale bar $=33 \mu \mathrm{m}$. 


\section{Figure 10: Immunohistochemistry of IL-6 and IL-8.}

Immunolocalisation (arrow) of IL-6 A, normal; B, 2 days; C, 6 days; D, 10 days; E, 20 days; F, negative control) and IL-8 (G, normal; H, 2 days; I, 6 days; J, 10 days; K, 20 days; $\mathbf{L}$, negative control) in the retinas of normal and eyes enucleated at 2, 6, 10 and 20 days after a BRVO was created.

Autofluorescence $(*)$ of inner segments is seen in most of the retinas including the negative control.

IL-6 is seen in the inner retinal layers. IL-8 is seen in the inner retinal layers.

ILM, Inner limiting membrane; ONL, outer nuclear layer. Scale bar $=33 \mu \mathrm{m}$. 


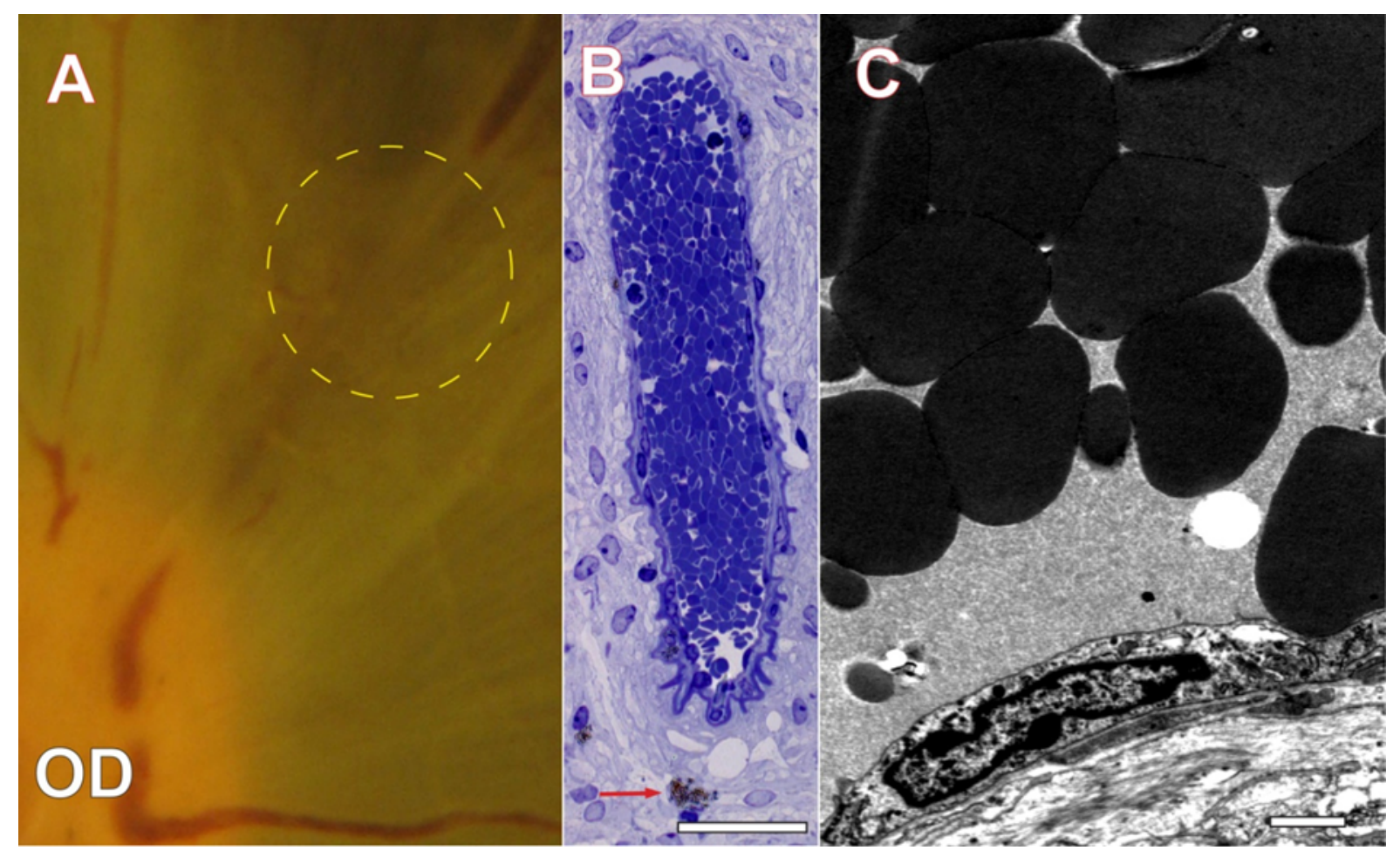

Figure 1 


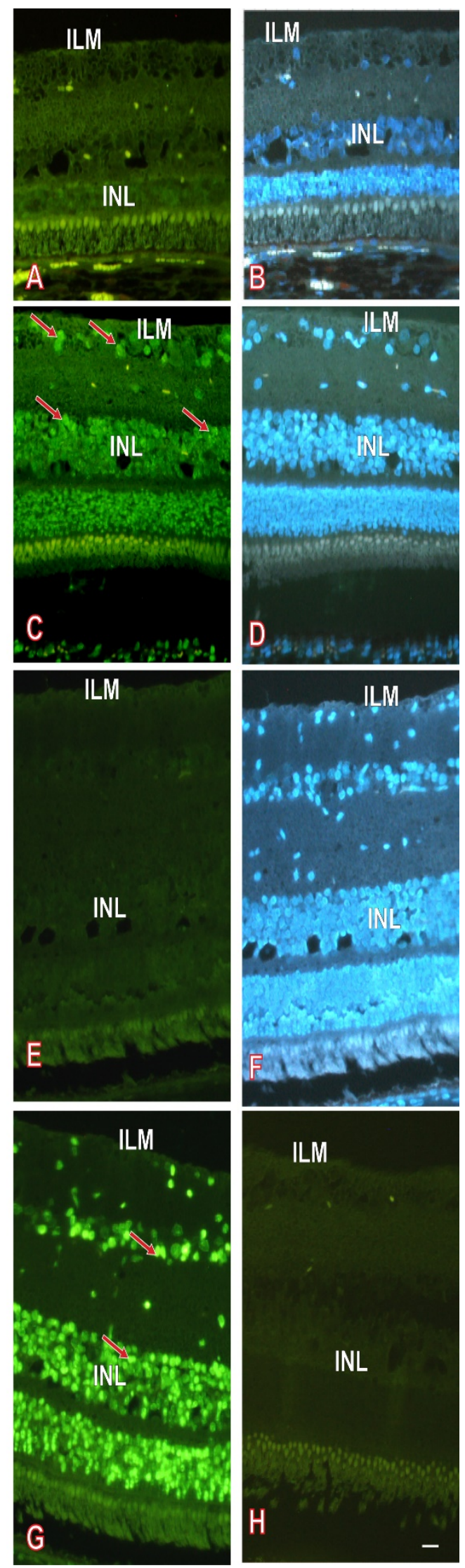

Figure 2 

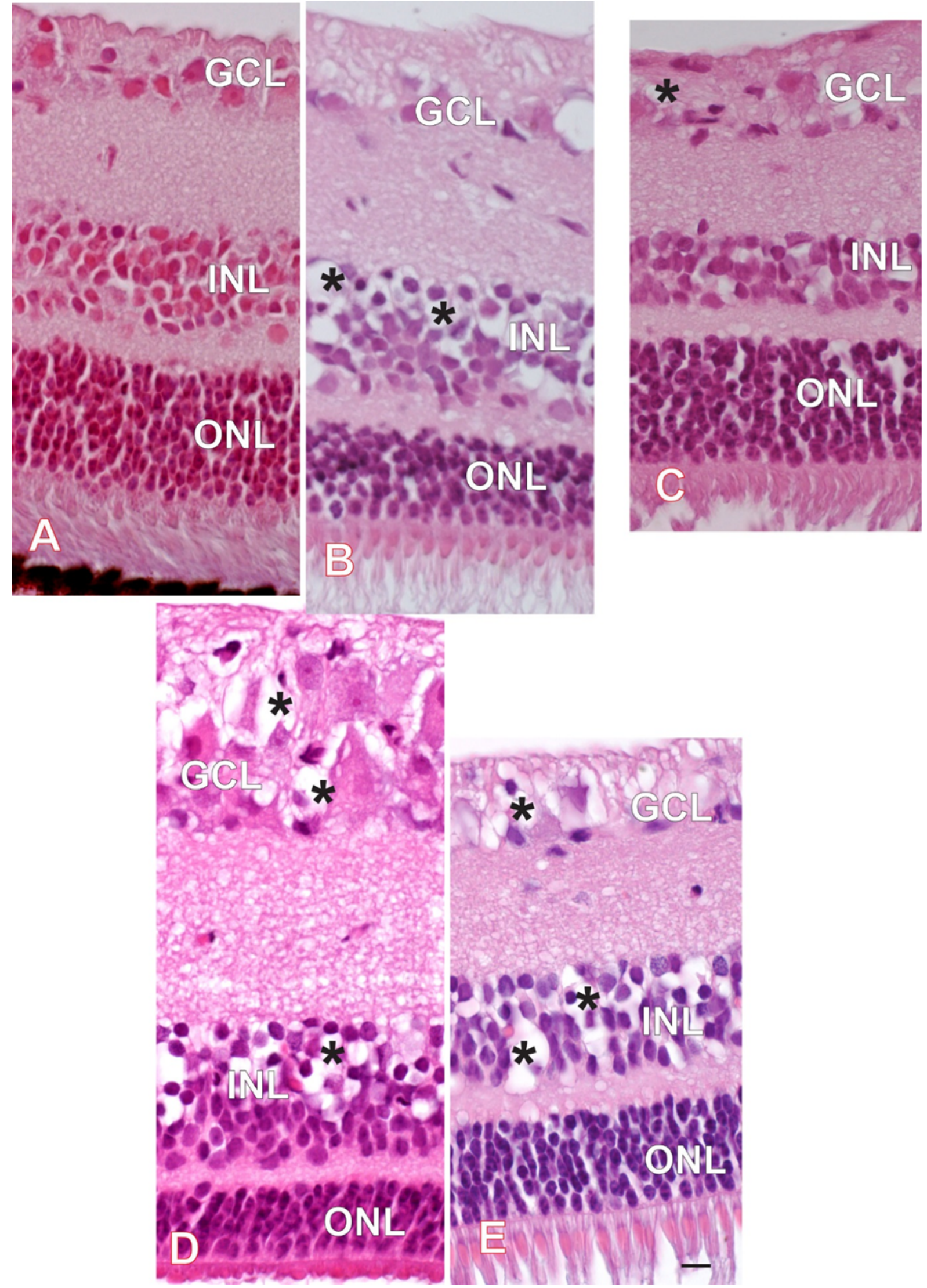

Figure 5 

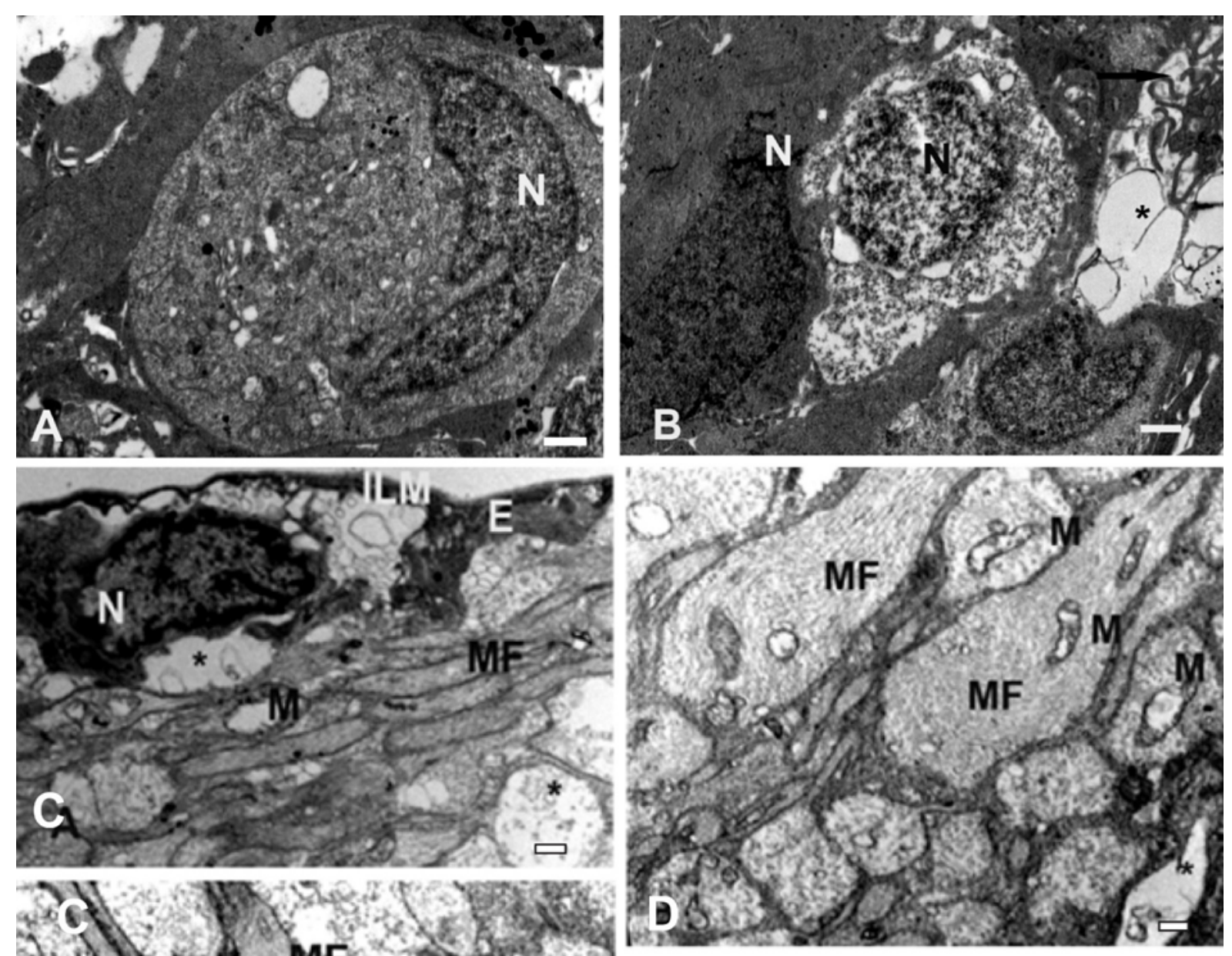

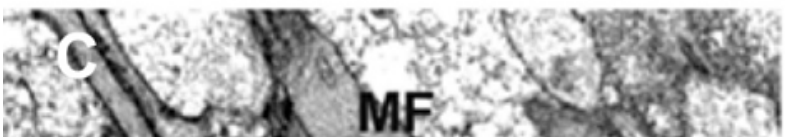
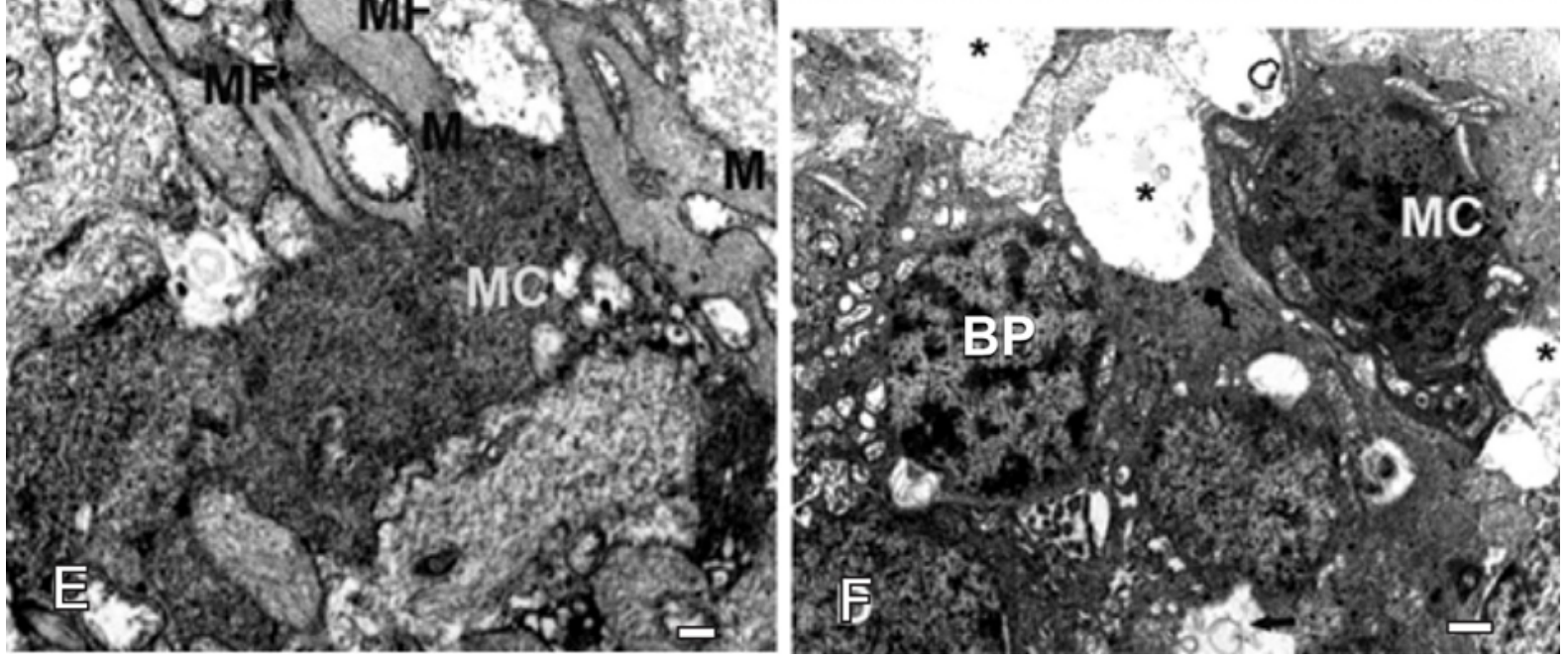

Figure 6 


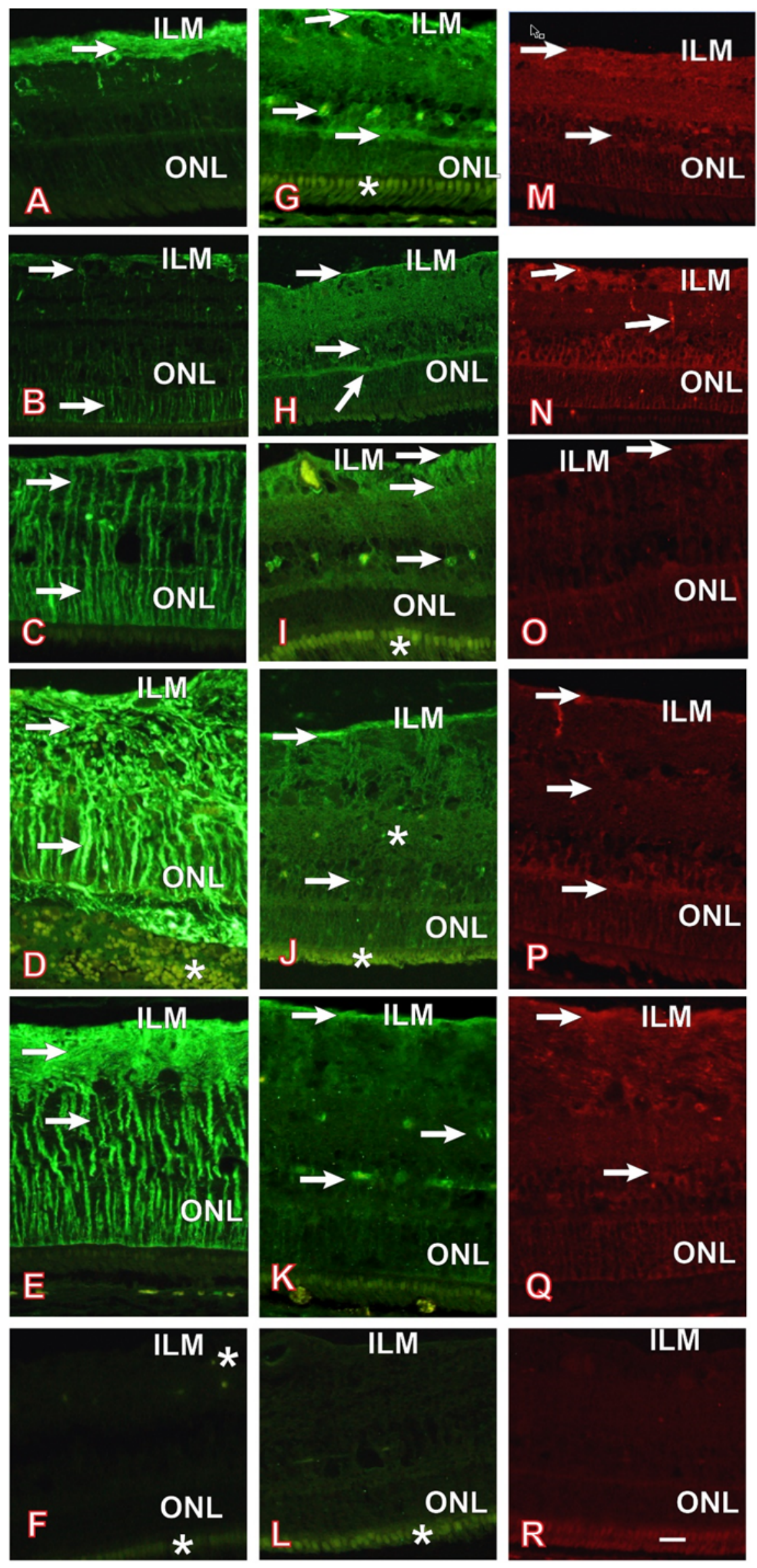

Figure 8 


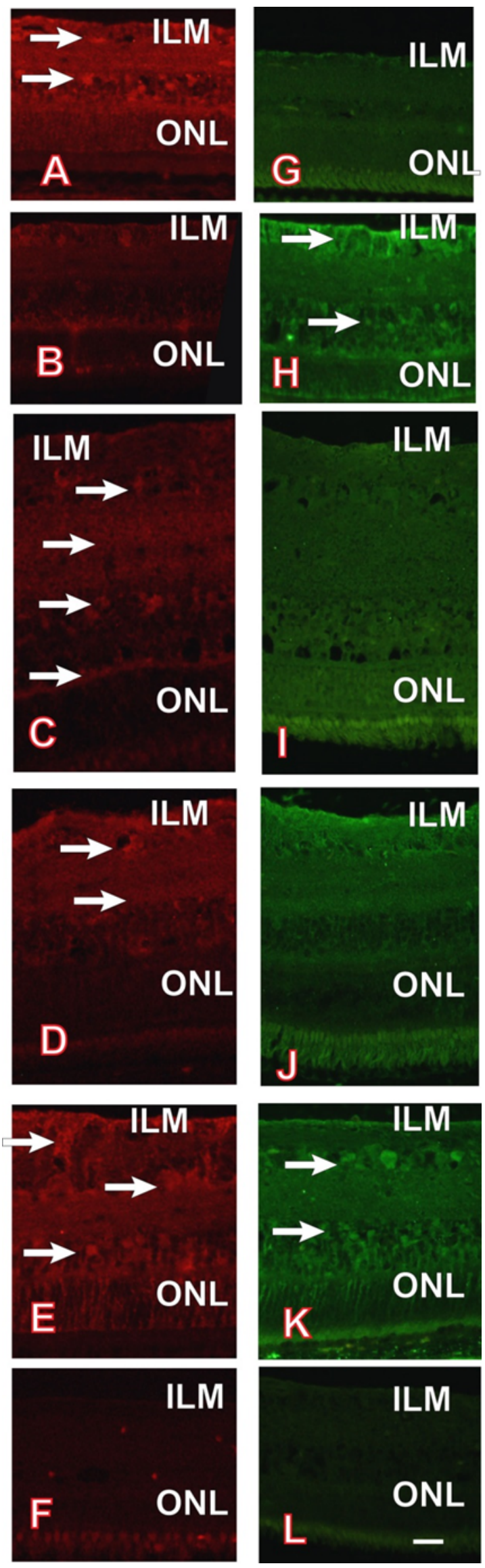

Figure 9 

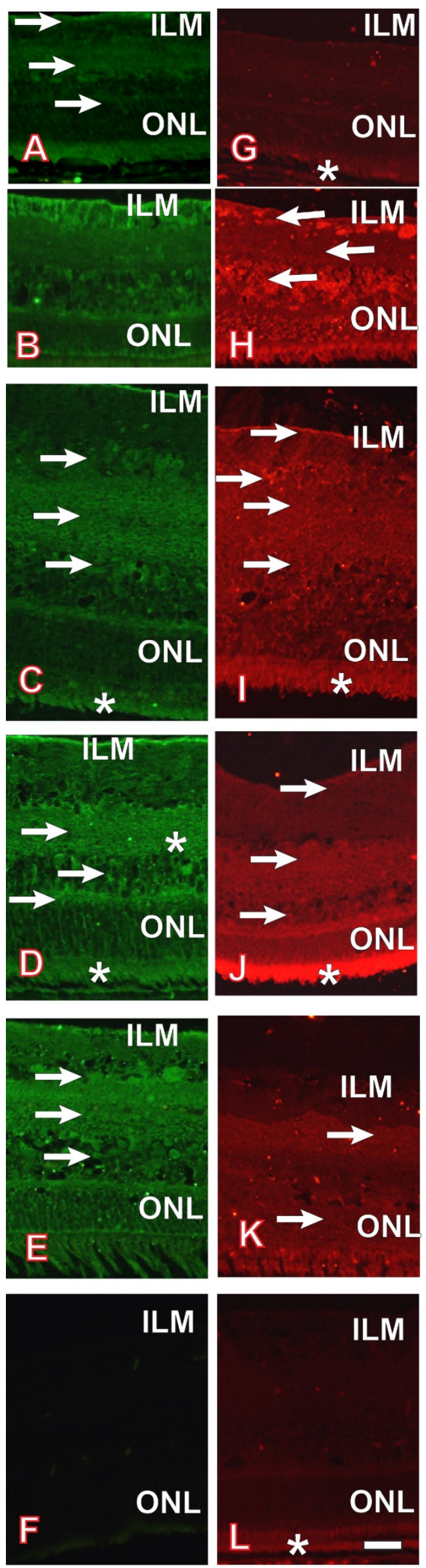

Figure 10 


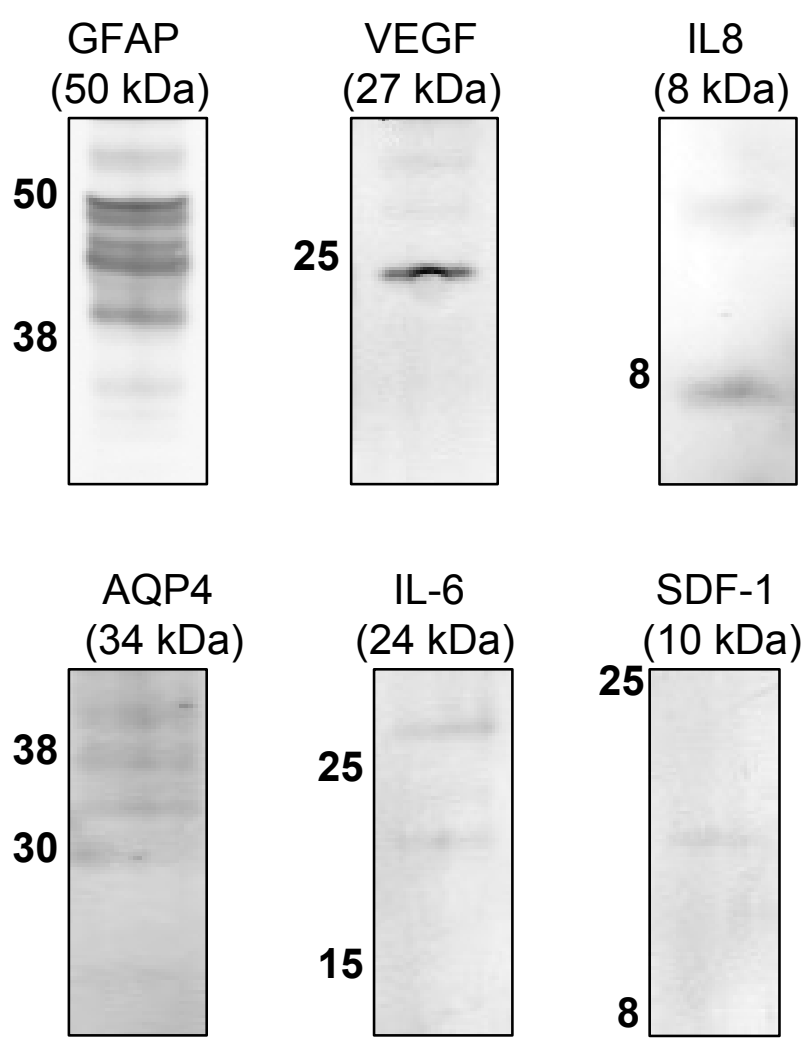

Antibodies were validated by western blotting against porcine retinal protein. Protein bands within the expected size ranges were labeled by all antibodies used in this study. GFAP, Kir4.1 and AQP4 antibodies labeled multiple bands in the expected size range, suggesting multiple protein isoforms or post-translational modifications. The signals produced by IL 6 and SDF-1 antibodies were low, due to the low abundance of these proteins in normal retina tissues. Mouse IgG1, rabbit lgG and goat lgG isotype control antibodies did not label any retinal proteins. Protein sizes are indicated in $\mathrm{kDa}$ to the Kir4.1 (42 kDa) Ms-IgG1 Rb-lgG Gt-lgG

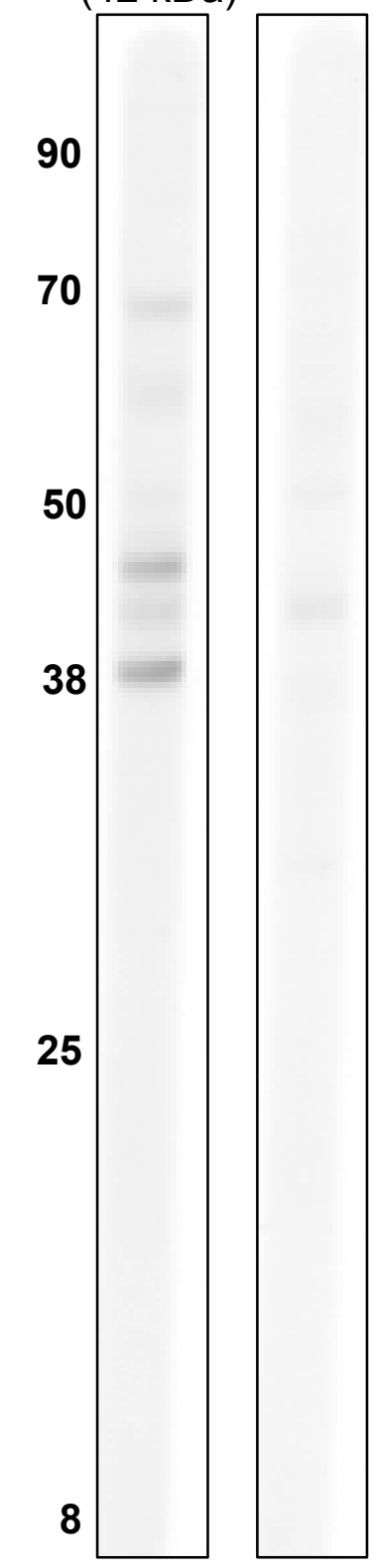
left of each blot. 